Board of Governors of the Federal Reserve System

International Finance Discussion Papers

Number 565

September 1996

Some evidence on the efficacy of the UK inflation targeting regime: an out-of-sample forecast approach

\author{
Chan Huh
}

NOTE: International Finance Discussion Papers are preliminary materials circulated to stimulate discussion and critical comments. References in publications to International Finance Discussion Papers (other than an acknowledgment that the writer has had access to unpublished material) should be cleared with the author or authors. 


\begin{abstract}
Inflation targeting (IT)--a policy framework that directly targets an explicit inflation goal--has gained widespread attention recently as it has been adopted by several OECD countries. There is a growing body of literature on the ultimate long-term benefits of price stability and on theoretical issues related to inflation targeting. But the short duration of this practice has limited the number of works that empiricalily analyze the performance of IT regimes. This paper examines the British inflation targeting experience since 1993 by focusing on the out-of-sample forecast performance of models fitted to the 1980s. The model over-predicts actual short-term and long-term interest rates, while it's inflation forecast is on track for the recent period. This implies that it took less monetary tightening to obtain a favorable inflation outcome. Identical exercises were repeated for France and the US, countries that have not adopted IT but have experienced low inflation in the recent period. The results for these countries show that recent low inflation has not been unusual when compared to forecasts from the models designed to fit the second half of the 1980s. That is, given the level of inflation, the degree of actual monetary policy tightness (measured in terms of short-term interest rate) is about what the model expects. Findings of this paper could be explained by enhanced credibility of the UK monetary policy since the adoption of IT.
\end{abstract}




\title{
Some evidence on the efficacy of the UK inflation targeting regime: an out-of-sample forecast approach
}

\author{
Chan $\mathrm{Huh}^{1}$
}

\section{Introduction}

Inflation targeting (IT)--a policy framework that directly targets an explicit inflation goal--has gained widespread attention in recent periods. ${ }^{2}$ The uitimate long-term benefits of price stability to be realized through inflation targeting are expected to be quite large. Also, a body of papers that discuss related theoretical issues, such as optimal designs of targets, has grown over time. However, the fact that these regimes have only been in place for a relatively short period of time has limited the number of works that empirically analyze the performance of recent IT regimes. ${ }^{3,4}$

This paper empirically examines the question of whether there have been perceptible changes (or structural breaks) in how key macroeconomic variables interact since the introduction of the IT regime in the United Kingdom. Adopting a Vector Autoregression (VAR) modelling framework, I focus on the out-of-sample forecast performance of models fitted to the 1980 s during the recent IT

${ }^{1}$ I received helpful discussions and comments from David Bowman, Dick Freeman, Joe Gagnon, and Deb Lindiner. I also gratefully acknowledge programming assistance by Robert İngenito and research assistance by Leslie Davis and John Heitkemper. Any remaining errors are my own. This paper represents the views of the author and should not be interpreted as reflecting those of the Board of Governors of the Federal Reserve System, or the Federal Reserve Bank of San Francisco or other members of their staff. Please address correspondence to: Chan Huh, Economic Research Department, Federal Reserve Bank of San Francisco, P. O. Box 7702, San Francisco, CA 94120. E-mail:chan.huh@sf.frb.org, tel: 415-974-2393.

${ }^{2}$ New Zealand (1990), Canada and Israel (1991), the United Kingdom (1992), Sweden and Finland (1993), and Spain (1994).

${ }^{3}$ For discussions of the long-term benefits, see Fisher (1994), King (1994). Various theoretical issues are discussed in Svensson (1993, 1996), Hall and Mankiw (1994), Woodford (1994), McCallum (1995). Ammer and Freeman (1995), Freeman and Willis (1995), the papers in Haldane (1995), and in Leiderman and Svensson (1995) offer detailed descriptive accounts on some of the countries that adopted IT.

${ }^{4}$ The UK has been one of the countries that implemented IT. However, the depth and breadth of financial markets set the UK apart. For further details of inflation targeting in the UK, see King (1994) and Bowen (1995). 
period. If there has been a noticeable structural shift, the manner in which forecasts of the model fitted to the earlier period mismatch the data in the 1990 s should offer clues about the change. In particular, we focus on the model's forecast errors during the IT period for inflation, the short-term interest rate, and the long-term interest rate to see if they show any unusual patterns. It should hold true that when monetary policy becomes more credible a less restrictive monetary policy would accompany low inflation, ceteris paribus.

An alternative way of gauging a structural shift is to assess changes in the terms of the tradeoff between output and inflation--i.e., the "sacrifice ratio". However, such an approach requires making a structural interpretation of estimated reduced form models. The thrust of this exercise is not to discern the nature of the dynamic relationships, but rather whether or not the structure of the dynamic relationship has remained intact throughout the sample period. Focusing on forecast performance consequently puts less demand on the estimated model

Furthermore, the IT immediately followed the UK's membership in the Exchange Rate Mechanism. During the ERM period, the British monetary policy stance was tight due to the need to support the pegged pound exchange rate prescribed by the ERM (Ammer and Freeman, 1995). Consequently, inflation was low when the inflation targeting monetary regime was first installed. This makes casting the UK's experience in terms of "sacrifice ratios" somewhat absurd."

Preliminary examinations are carried out using a VAR model of the UK economy consisting of six quarterly variables estimated using data up to $1990 .^{6}$ The fit of the model to later periods

\footnotetext{
${ }^{5_{T h}}$ This is in strong contrast to New Zealand's experience during the period leading up to IT. A protracted period of monetary tightening was necessary to bring down inflation which was at 15 percent, incurring a substantial output loss. Hence, the "sacrifice ratios" gained currency as the measure of effectiveness of the IT monetary regime. See Mayes and Chapple (1995) for a critical review of this issue.

${ }^{6}$ The variables are: real GDP growth, unemployment rate, inflation in retail price index (RPIX), the tradeweighted pound exchange rate, short-term interest rate, and long-term interest rate. The last two each relate to monetary policy stance and inflation expectations plus risk premium.
} 
deteriorates drastically, suggesting instability in the model. To further investigate these preliminary observations, a VAR with Bayesian priors (BVAR) is estimated. The baseline model that represents macroeconomic dynamics up to the late 1980 s is estimated using data from the corresponding period.

The results show a noticeable divergence in the model's forecast performance since 1990 with respect to inflation and the short-term interest rate and, to a lesser extent, the long-term interest rate. The model's inflation forecast had large forecasting errors (over-prediction) during the ERM periods and the early part of the IT period. However, this over-prediction bias disappeared rapidly. The longterm interest rate forecast showed no clear bias until the beginning of the IT period. Then, the model consistently over-predicted the actual long-term rate. Most noticeably, the model consistently over-predicted short-term interest rates throughout the inflation targeting period after showing a reasonable fit during the ERM period. In short, despite a monetary policy stance that has not been as tight as the model would suggest, inflation has remained close to the model's forecast. The actual long-term rate aiso has been lower than the model's prediction, suggesting lower-than-expected inflation expectations and inflation risk premium in later periods.

One could attribute such constellations of forecast errors to an enhanced credibility of monetary policy. That is, monetary policy has become more effective in the sense that it takes less actual tightening to obtain a favorable inflation outcome as markets expect future monetary policy to be conducted along a path compatible with maintaining low inflation. Alternatively, favorable price shocks, such as a fall in import prices, could also explain low inflation. However, there have been several developments such as sterling depreciation during the period that have put upward pressure on

\footnotetext{
${ }^{7}$ The BVAR framework, which was developed by Litterman and Sims based on Theil's (1972) mixing estimation methodology, is suitable for this exercise. It entails specifying a set of parameters that represent prior knowledge about the structure of the economy, which is used in conjunction with actual data for the estimation of the model. We determine these parameters in an optimizing fashion using data from 1985 to 1990. They in turn are fixed when forecasting the out-of-sample period (1990-1995). in this sense, they represent a salient data structure of the 1985-1990 period.
} 
inflation. Hence the explanation of enhanced monetary policy effectiveness becomes plausible.

A moderating inflation trend has not been unique to the UK but has been seen in many OECD countries in the 1990s. Presumably, the recession that visited major G-7 countries at the beginning of the 1990s could have caused this. However, the moderate trend has continued even when most of these economies moved well into recovery phases. This raises the possibility that the earlier finding of the mis-match between inflation and interest rates might not be unique to the British economy and particularly may have little to do with the institution of inflation targeting.

To test this possibility, the identical exercise was repeated using data from the US and France, two countries that have not adopted explicit IT monetary policy regimes. The results for these countries show that recent low inflation has not been unusual when compared to forecasts from the models designed to fit the second half of the 1980s. That is, given the level of inflation, the degree of actual monetary policy tightness (measured in terms of short-term interest rate) is about what the model expects. Hence, it is unlikely that this paper's results on the UK are mainly due to an exogenous low inflation trend commonly seen in most OECD countries, but not captured by the model.

A caveat to this paper's finding is in order. Despite the low and stable inflation in the 1990s, indicators of long-term infiation expectations have not shown noticeable change. One indicator is the yield spread between the British and the German long-term securities. Though the spread is narrower in the 1990 s compared to the 1980 s on average, it has not narrowed noticeably during the recent period. Survey measures of inflation expectations also have declined at a glacial pace. ${ }^{8}$ They seem to reveal lingering doubts about whether current low inflation can be extended into the future. This in

\footnotetext{
${ }^{8}$ However, an indicator of inflation expectations derived froma à compāarison of conventional and infiationindexed bond yields show some change in patterns in the 1990s. Current inflation expectations measures for five and ten-year horizons respectively 150 basis points lower than its peak seen in early 1994 (5-years) and in 1992-93 (10-years). However, both the current levels of the both measures are 2 to 3 percent higher than the prevailing inflation rate (p. 47, Inflation Report (1996)).
} 
turn illustrates the difficulty of estaslishing long-term credibility of monetary policy.

The remainder of the paper proceeds as follows. Section II reviews UK economic developments in the late 1980s and early 1990s. Section III describes the model and its estimation, respectively. Results are examined in Section V, and Section VI concludes.

\section{Economic Developments in the United Kingdom: 1985-1992}

The British monetary authorities focused, in turn, on broad as well as narrow monetary aggregates as intermediate targets in the mid-1980s. Starting in the second half of the 1980 s, the focus started to shift to exchange rates as the pound sterling steadily appreciated against the German mark. This began around the period of the 1985 Plaza Accord and the Lourve Accord of 1987, at which time major industrialized countries agreed to lower the value of the dollar and to maintain stability in key exchange rates. A widening external imbalance brought about by rising imports in 1986 also contributed to Britain's shift to managing exchange rates around that time. External balances, which first recorded a current account deficit of $£ 1.5$ billion in 1986 after several years of surplus, deteriorated rapidly and reached about $£ 29$ billion in 1988 fueled by a strong domestic demand for imports. GDP grew at 4 to 5 percent annually in real terms between 1985 and 1988 .

In the meantime, the annual inflation in consumer prices, after ebbing to 4 percent in 1986 , started to rise along with a surge in the domestic demand. This was followed by a substantial depreciation (about 10 percent) of the pound exchange rate in 1989. However, this fall in the pound exchange rate was arrested as the short-term interest rates were raised by about 2 percentage points to 15 percent at the end of 1989 . Though short-rates gradually fell thereafter, it was not until March 1991 that the rates fell to where they had been in January 1989.

The exchange rate remained stable throughout 1990 and 1991. At the same time, output growth that averaged about 4 percent in the preceding five years first sharply contracted in the third 
quarter of 1990 and then continued to be negative throughout 1991 . On the other hand, inflation measured in terms of the year-over-year retail price index excluding mortgage interest payment reached a peak of 9-1/4 percent in the fourth quarter of 1990. This increase, from a 6 percent range a year earlier, was partly due to the run-up in oil prices associated with the Gulf-crisis. A substantial output contraction notwithstanding, both this high inflation as well as the need to support the pound exchange rate initially severely limited the options available to monetary authorities. In particular, due to high German interest rates associated with the financial burden of the unification, the UK rates had to be kept high to defend the pegged sterling exchange rate. On the fiscal policy side, the government's budget balance, which maintained a surplus for several years after 1987, also started to deteriorate significantly starting in early 1991. By late 1991, the situation became more and more untenable. Finally sterling left the ERM in September 1992 when it came under overwhelming pressure caused by a large-scale selling of sterling in the foreign exchange markets. This withdrawal subsequently left no nominal anchor to guide monetary policy. In October, the Chancellor of Exchequer announced the adoption of IT.

\section{Estimation}

One way to examine the impact of this sequence of events on the relationship how variables interact is to rely on a general model. For such an investigation, a VAR model of six variables was fitted to the UK data as follows;

$$
\begin{gathered}
X_{t}=D+\sum_{i=1}^{n} \boldsymbol{B}_{i} X_{t-i}+\boldsymbol{e}_{t}, \\
E\left[e(t) e(s)^{\prime}\right]=\mathbf{\Sigma} \text { if } s=t,
\end{gathered}
$$

Here $X=\{y, u n, \pi, e x, s r, l r\}: y$; real GDP growth, un; unemployment rate, $\pi$; inflation in retail 


\section{$=0$ otherwise.}

price index net of mortgage interest payments (RPIX), sr; short-term interest rate as the key measure of monetary policy, ex; trade-weighted nominal pound exchange rate, and $l r$; the long-term interest rate. ${ }^{2}$ Figure 1 shows data series for the period $1985 \mathrm{Q} 1$ to $95 \mathrm{Q} 3$. First, the model is estimated using data from 1972Q1 to 90Q2. Next, whether this specification remains stable is examined by inspecting residuals generated by fitting the model to data of the sample period not used for the estimation (i.e, 1990Q2-95Q3).

Figure 2 shows two sets of residuals from the equations for inflation, short-term and long-term interest rates. The top panel shows residuals from the model estimated from 1972Q1-90Q2, and the bottom panel shows those from the model estimated from 1972Q1-92Q3. These particular dates are chosen since the first denotes the UK's joining of ERM, and the second for the UK's withdrawal from the ERM and the beginning of the IT regime. Two standard error bands for each residual are also shown. The mis-match between the data and the model for the post-ERM period is evident. The model's infiation forecast under-predicts inflation and over-predicts interest rates. This tendency diminishes noticeably for inflation and the long-term interest rate, but persists for the short-term interest rate when the model estimation period is extended to include the ERM period (i.e., 1990Q392Q3). The standard error band for the long-term interest rate forecast also noticeably widened.

These observations suggest that there has been at least one perceptible break in the sample period. This bodes well with the events in the British economy. In particular, the ERM and the

\footnotetext{
${ }^{9}$ The real GDP index excluding the oil sector is used as the output variable. Inflation is measured in terms of the retail price index excluding mortgage interest payment. The X-11 filter was applied to the price index, RPIX, to remove seasonality before calculating inflation rates. A trade-weighted nominal average exchange rate compiled by the Bank of England is used as the pound exchange rate. For the short- and long-term interest rates, the rates on the 3-month interbank loan and on the 3-1/2 percent war loan (consol) are respectively used. Growth rates of real GDP and the RPIX (ie., inflation) are used. For the rest of the variables, logged series were used. The lag length of six was determined by testing various alternatives using the log-likelihood ratio test of Sims (1980). Using the real exchange rate, instead of nominal, did not materially affect the results.
} 
adoption of the IT regime each could offer distinct demarcation points. To push this further, I follow a variant of the VAR modeling approach, namely, VAR with Bayesian priors developed by Litterman (1984) and Sims (1982) based on the mixing estimation methodology of Theil (1972). The BVAR has mainly been used to improve long-term forecasting accuracy by estimating coefficients using both data and reasonable priors. ${ }^{10}$

This framework is useful since a modeler can choose specific values for the priors by means of optimizing criterion to a particular sub-sample period. Thus, one could tailor the model specification to incorporate the dynamic structure of the data, or economy, in the sense of a set of prior restrictions on coefficients. Consequently, by fixing the priors to the values determined at the earlier stage in subsequent estimations, one could preserve the dynamic structure of the baseline estimation period. This idea is implemented in the following way: First, an ordinary VAR was estimated using data from 1973Q2 to 84Q4. Second, a set of hyper-parameters representing 'priors' are determined so as to minimize the one- to fnur-quarter ahead out-of-sample forecast of the VAR model for 1985Q1-90Q2. The end-product of step two is the BVAR version of (1).

The prior distributions for the coefficients $\left(b_{i} s\right)$ are specified as follows:

$$
\begin{gathered}
\tilde{b}_{i} \sim N(1, f(\alpha, \beta, \gamma)), \text { for } i=1 \text { and } \\
\tilde{b}_{i} \sim N(0, f(\alpha, \beta, \gamma)), \text { for } i>1 .
\end{gathered}
$$

Here the subscript i denotes the lag length. This set of priors amounts to a random walk with a drift."

\footnotetext{
${ }^{10}$ The prior information is introduced in the way of hyper-parameters that influence, in each equation, the degree of interaction with dependent variable's own lags as well as across different variables in general, rather than specific individual coefficients.

"Alternatively, AR(1) coefficients estimated using the initial sample period (1972-1984) were used as the prior values. Results were not sensitive to such changes in the prior.
} 
The variance of the prior distribution for a coefficient is given as $f($.$) , which inversely reflects the$ degree to how certain the prior being imposed should be. That is, a small $f($.$) suggests that the chosen$ prior is very tightly distributed around the mean value. A large value for $f($.$) conversely suggests that$ the imposed prior has a large variance, hence a loose prior. The final estimation of coefficients is done by combining the prior and the actual data. Relatively speaking, the larger $f($.$) , the stronger the$ influence of actual data on determining the coefficients. ${ }^{12}$

To be specific, the values for the hyper-parameters $\alpha, \beta$, and $\gamma$ were chosen to optimize the model's out-of-sample forecast performance of the VAR model estimated from the first stage for the sample period 1985Q1-90Q2. The optimization involves an objective function consisting of the sum of Root Míean-Squared-Errors over one- to four-quarter ahead forecasts.

(2) $\quad F()=.\sum_{k=1}^{4} w_{k} \sum_{m=y}^{l r} z_{m}[R M S E[\operatorname{actual}(m, t+k)-\operatorname{forecast}(m, t, k)]]$,

where $w_{i}$ and $z_{m}$ are respectively indexes for the forecast horizon, and the variables whose forecast errors are included in the objective function. The index $k$ represents the forecast horizon. For example, the following expression stands for the difference between the output growth two periods

\footnotetext{
${ }^{12}$ The variance $\mathbf{f}($.$) is determined as a function of three parameters; \alpha, \beta$, and $\gamma$. The three parameters each represent the overall tightness of the prior, how fast the influence of lagged values decay, and the degree of cross-variable dynamics. For example, the element $\beta$ dictates the rate of decrease in the value of $f($.$) as the lag$ length increases. Additionally, the parameter i dictates the influence of $\left(\pi_{\mathrm{t}-2}, \pi_{\mathrm{t}-3,}, \pi_{\mathrm{t}-4}, \ldots, y_{\mathrm{t}-2}, y_{\mathrm{t}-3}, y_{\mathrm{t}-4}, \ldots, s r_{\mathrm{t}-2}, s r_{\mathrm{t}-}\right.$ $\left.{ }_{3}, s r_{\mathrm{t}-4}, \ldots ..\right)$ on $\pi_{\mathrm{t}}$. Thus, a rapid decay means a tighter prior on the lagged values of the variable. Equivalently, it reduces influences from lagged values.

The parameter $\gamma$ would determine how much the other variables (eg., $y_{t-1}, y_{t-2}, y_{t-3}, \ldots, u n_{t-1}, u n_{t-2}, u n_{t-}$ ${ }_{3}, \ldots ., s r_{t-1}, s r_{t-2}, s r_{t-3}, \ldots .$. ) could influence $\pi_{t}$. A larger $\gamma$ allows more influence from other variables in the inflation equation. For example, a combination of rapid decay and a small $\gamma$ would reduce the role of lagged values beyond the first lag, and at the same time, reduce the role of the other variables. Hence, this combination pushes the model towards a univariate random walk specification. For further detailed descriptions, see pp. 8-17 - 8-23 of RATS 4.2 manual.
} 
hence and the two-quarters-ahead output growth forecast the model made at time $t$. In the current estimation, $w_{i}=1, z_{m}=1$ for $\mathrm{i}=1-4$ and all $m \mathrm{~s}$. That is, the objective function includes all variables, and their one- to four-quarter ahead forecast errors are equally weighted. ${ }^{13}$ A numerical search procedure was carried out over grids which define six different settings for three hyper-parameters (eg. there are $6^{3}$ possible combinations) to minimize the objective function. ${ }^{14}$

The sample period begins in 1985 . This is to allow for the fact that a new regime might have been introduced in 1979 with the beginning of the Thatcher administration. Five additional years are allowed as an adjustment period. The sample period ends with the UK's participation in the ERM in 1990Q2.

In addition to the RMSE, three types of accuracy measures are used in this exercise. They are: (1) mean errors (ME), (2) mean absolute errors (MAE), and (3) Theil's U-statistics. (1) and (2) together convey information about the tendency of bias in the model's forecast. Suppose that the ME is negative, and at the same time, the absolute size of the ME is close to the corresponding MAE for the same forecasting periods. This would indicate that the model consistently over-predicts over time (assuming forecast errors are measured as actual minus forecast). The Theil's U-statistics are used as an indicator of the overall goodness of the forecast.

This statistic is useful in particular because it offers a unit-free comparison of the model's

\footnotetext{
${ }^{13}$ I.e., the two-quarter-ahead forecast error:
}

$$
\text { actual }(y, t+2) \text { - forecast }(y, t, 2) \text {. }
$$

One could set some $z_{m} s$ to zero, or exclude the RMSEs of a subset of variables when designing a model. Similarly, one could choose a particular combination of forecast horizon(s) by setting some $w_{i} s$ equal to zero.

${ }^{14}$ The process can be described as follows: Pick a point on the $6{ }^{3}$ grid of the hyper-parameter values. Then, one- to four-quarter ahead forecasts are made for the sample period from 1985Q1-90Q2 where the coefficients are sequentially updated over time after each forecast. The forecast errors are compiled for the whole forecast period. This is repeated for ail possible settings of the hyper-parameter values and forecast errors for each setting of the hyper-parameters are scored. The optimal setting is chosen by selecting the one that is associated with the minimum RMSE. 
forecast against a random-walk model based forecast, or a no change forecast. It is calculated as the ratio between the RMSEs of the model's forecast and no-change forecast. Thus, a Theil statistic value greater than one indicates that the model's forecast is less accurate than that of a random-walk model, and one could do better relying on the no-change forecast.

Table 1 shows the statistics for the current model. Examinations of different statistics suggest that the specification is reasonable. The mean-errors and mean-absolute-errors together suggest that the specification does not have a consistent over- or under-prediction bias. At the same time, Theil's U-statistics show that the model forecast is superior to the no-change forecast, with the exception of the pound exchange rate.

\section{Resultis}

Once the hyper-parameter values are chosen, we generate out-of-sample forecasts starting with 1985Q1. Then the forecast accuracy statistics for rolling ten-quarter intervals are compiled. For example, the first interval started 1985Q1 and ended $87 \mathrm{Q} 2$. Similarly, the last interval is from $1993 \mathrm{Q} 2$ to $95 \mathrm{Q} 3$. We apply this rolling method for both one- and four-quarter-ahead forecasts. For the fourquarter-ahead forecast, the model started forecasting 1984Q1, so the first four-quarter-ahead forecast is for $85 \mathrm{Q} 1$.

For the purposes of exposition, a ten-quarter interval is treated as the unit interval for measuring forecast accuracy. This allows us several observations belonging exclusively to the IT period. ${ }^{15}$ The forecast accuracy statistics of these two periods are then compared with the rest of the sample periods, allowing one a 'small sample' feel about how close the model's forecasts are.

Furthermore, if there is a distinct pattern in the accuracy measures, we might be able to make an

\footnotetext{
${ }^{15}$ Note that the United Kingdom withdrew from the ERM in September 1992, and inflation targeting was introduced thereafter. Accordingly, we have two out-of-sample observations that are entirely made up of IT period data; one for 1993Q1-95Q2, and the other for 1993Q2-95Q3.
} 
educated guess on its connection to the IT regime that has been in place since 1993.

The figures show the forecast accuracy statistics for the rolling ten-quarter horizons. Figures with the suffix A (eg. 3.1.A) show MEs and MAEs on the same panel. For example, Figures 3.1.A and 3.4.A show the mean errors and mean absolute errors of the one-quarter-ahead and four-quarterahead inflation forecasts, respectively. Each point represents the ME and MAE for a ten-quarter interval ending at the date shown on the horizontal axis. Figures with the suffix B show Theil's Ustatistics. For example, Theil's U-statistic dated 1995Q1 represents the statistic calculated from the ten-quarter forecast horizon from the third quarter of 1992 through the first quarter of 1995.

Figures 3 through 5 respectively show the model's inflation, short-term interest rate, and the long-term interest rate forecasts. The observation of these three variables jointly is interesting in that each represents actual inflation outcome, the stance of monetary policy, and inflation expectations and risk premium, in turn.

\section{A. The ERM period: 1990 Q3 - 92Q4}

There are some perceptible differences across these three sets of graphs. First, a marked deterioration in the forecast accuracy sets in at different times across variables. Both for inflation and the long-term interest rate, the model first starts to over-predict, hence the forecast performance noticeably worsens starting sometime around the end of 1988, or the beginning of 1989 . However, it was not until the end of 1990 , or the beginning of 1991 when the performance of the short-rate forecast started to deteriorate. Hence, there is at least a one year gap between the time the forecast performance started to get worse for the three variables.

The ERM regime started in the third quarter of 1990 . Thus, the behavior of inflation and inflation expectations/premium captured in the long-term interest rate during the period starting in late 
1988 through late 1990 could be attributed to an anticipation effect of the onset of the ERM regime. ${ }^{16}$ That is, once it became likely that the U.K. would participate in the ERM, markets anticipated a continuation of tight monetary policy to support a stronger pound exchange rate. Given that inflation was relatively high during these periods (RPI inflation of 4.4 and 5.7 in 1988 and 1989), the nominal rate had to be pushed up to support the real short-term interest rate around 5 percent, which was the level seen in 1987. In fact, the yield curve remained inverted throughout this period as short-term rates were higher than long-term rates since the second quarter of 1988 . This, in turn, implied lower future inflation as well as sluggish activity. Both actual inflation and the long-term interest rate thus reflected these, and adjusted even before the actual inauguration of the ERM regime.

Since the model did not have this information, however, it persistently over-predicted actual inflation during the ERM period. In addition, there was a surge in RPI inflation in the second quarter of 1990 caused by the Gulf crisis. This, in turn, generated a very large forecast error as the model's forecast was far below the actual. The model took this to be a large unanticipated price shock and hence it introduced an upward bias in inflation forecast for subsequent periods.

In terms of the short-term interest rate forecast, the model did not have the same information about the ERM. Hence, the persistent high short-term interest rate in late 1991, or the lack of lowering of rates, in the face of weak output came as a surprise. This explains the under-prediction of the short-rate around 1989-1992, as shown in figures 4.1.A and 4.4.A.

\section{B. Inflation Targeting Period: 1993Q1 -95Q3}

\footnotetext{
16"Statements by the Chancellor of the Exchequer soon after the meeting of the Group of Six Financial Ministers in Paris.....gave the indication that the authorities were pursuing an unannounced exchange rate target." (p.17, Paul Temperton, 1990). There was widely known discord between Chancellor Lawson (pro-ERM) and Prime Minister Thatcher which led to the ultimate removal of Lawson from his position in September 1989. However, perhaps the need to find an anchor to guide monetary policy and the importance of the external sector to the economy might have been perceived to be more overwhelming.
} 
Next, we turn to the post-ERM IT period. Let us first turn to the short-term interest rate forecast. An examination of Figures $4.1 \mathrm{~s}$ and $4.4 \mathrm{~s}$ show that the model consistently over-predicted the actual short-term interest rate. Though the ME and MAE appear to have reached a peak in 1994, the Theil statistics do not show a similarly improving trend. For example, the Theil statistic for the 10quarter interval 1993Q2-95Q3 is 1.484 , which is the largest in the whole sample. The same statistic for the interval $1993 \mathrm{Q} 1-95 \mathrm{Q} 2$ is the third largest in the whole sample. This becomes particularly obvious in the case of the four-quarter-ahead forecast. The last two observations (for 1993Q1-95Q2 and 1993Q2-95Q3) are the two largest in the whole sample shown in figure 4.4.B. To the extent that this 3-month interest rate represents the stance of monetary policy, the model's overwhelming overprediction suggests that monetary conditions may have been looser than the model would have anticipated, based on past experiences.

In contrast, the model's inflation forecast markedly deteriorated in late 1992 and/or early 1993, then improved rapidly. Such a pattern is clearly visible in all measures shown in Figure 3s. Particularly, with an exception of the four-quarter-ahead Theil, the inflation forecast noticeably improves in the last two forecast intervals that begin 1993Q1 and 93Q2. This pattern of improvement is in marked contrast to the case of the short-term interest rate.

The long-term interest rate also exhibits a similar but much subdued pattern of improved forecast performance in the last two observations. In this case, the improvement is more visible in the four-quarter ahead forecast, though the one-quarter ahead forecast also shows gradual improvement. A comparison of MEs and MAEs in both inflation and the long rate cases indicates that the model's forecast became less biased, unlike the ERM period that preceded the inflation targeting regime.

These observations jointly suggest the following interpretation. To use the model's short-term interest rate forecast as a benchmark, monetary policy has not been overly restrictive. That is, the 
model expected the short-term rates to be higher than they actually turned out to be in the post-1993 sample period. However, despite these lower-than-expected configurations of the short rates, actual inflation had converged rapidly to where the model expected it to be. To the extent that the long-term interest rate proxies the inflation expectation and inflation risk premium, the model also over-predicted these over this period. Though changes in the credibility of monetary policy in this inflation targeting period is the likely explanation, other possibilities warrant our attention.

A positive supply shock could explain such an outcome. The sterling has depreciated more or less continuously since 1992 . Though this is a favorable terms-of-trade shock, it has a definite inflationary implication. For example, the unit value of imports increased by 10 and 3.4 percent, respectively in 1993 and 1994 . At the same time, there has been no evidence of extraordinarily favorable price shocks. In fact, the producer price index for input factors rose 4.7, 2.9, and 9.4 percent respectively for 1993, 1994, and 1995.

Another possibility is that there was a favorable inflation environment in the form of low wage pressures during this period. Indeed, there have been few perceptible pressures on wages and unitlabor costs in the recent period, even with the robust activity seen in 1994, for example. The pace of growth in average earnings slowed to around 3-3/4 percent (from about 6 to 7 percent) in the last three years. This moderation in wage pressures could be attributed to cyclical as well as structural factors. The official claimant-count based unemployment rate has declined noticeably since the 1990-92 recession. However, the labor force participation rate has not increased proportionately, suggesting some residual slack in the labor markets. In addition, a large scale privatization of public corporations and a weakening labor union have been important changes British labor markets since the early 1980s. These developments affected patterns of wage settlements and hence should have influenced wage behavior in recent periods. However, a low inflation environment and increased credibility of a low inflation monetary regime must have been factors contributing to such wage behavior. Workers would 
settle for a smaller rise in nominal wages if they expect slower erosion of the purchasing power of their nominal wages over the contract period, ceteris paribus. Hence, a lack of wage inflation can not be an independent explanation of the observed changes in the forecast performance pattern since 1990.

Improvement in the effectiveness of monetary policy still remains a likely explanation. That is, despite a monetary policy stance that has not been as tight as the model would suggest, inflation has remained close to the model's forecast. The model also expected a higher long-term interest rate (larger inflation expectations and risk premium). The UK monetary policy has become more effective in the sense that it has taken less tightening to obtain a favorable inflation outcome. This would not have been possible if markets fully discounted the credibility of the new IT regime.

On the other hand, a moderating inflation trend has not been unique to the UK but has been seen in many OECD countries in the 1990s. Presumably, the recession that visited major G-7 countries at the beginning of the 1990 s could partly explain this observation. However, the moderating trend has continued even when most of these economies moved well into recovery phases. This raises the possibility that the earlier finding of the mis-match between inflation and interest rates might not be unique to the British economy and particularly has little to do with the institution of inflation targeting. This possibility is examined in the next section.

\section{Cross country comparison: France and the US}

This section examines results from the identical exercises repeated for the key G-7 countries that have not adopted an explicit IT regime, namely, France and the US. ${ }^{17}$ Panels in Figure 6 show

\footnotetext{
${ }^{17}$ Quarterly data from 1972-84Q4 were used for the initial estimation, 1985Q1-90Q2 for the hyper-parameter estimation, and 1990Q3-95Q3 for the out-of-sample forecast. The same set of six variables are used; growth in real GDP, inflation in consumer price indexes, short-term interest rates (one-month Paris interbank money market rate for France, and 3-month T-bill for US), long-term interest rates (long-term bellwether bond yield for France, and 10-year rate for US), trade-weighted exchange rates, and unemployment rates. Parameter and weight setups
} 
the inflation forecast errors for France and the US models respectively. The comparable figures from the British model are shown as dotted lines in all graphs to facilitate a direct comparison. In general, forecast errors for the two economies are smaller and less erratic. There is no discernable bias tendency in a one-quarter-forecast horizon. Over a four-quarter-forecast horizon, the model's forecast performance for France somewhat temporarily worsened in the early 1990s, but otherwise no clear trend can be found. Interestingly, according to the Theil's statistics for the four-quarter-ahead forecast, the US model has distinctly been over-predicting actual inflation since 1993 in terms of the Theil statistics. This corroborates well with the perception that inflation in the US has become unusually well-behaved in the recent period.

Panels in Figure 7 show forecast errors for the short-term interest rate. For France, rising MAE and a falling ME pattern seen in a one-quarter-ahead forecast suggests that the model tended to over-predict short-term interest rates since 1993. However, this does not suggest a significant bias as patterns in both four-quarter-ahead MAE and ME and Theil statistics do not indicate such a tendency. On the other hand, both MAE and ME have been approaching the horizontal line from above and below in the recent period. This suggests that errors are small and evenly distributed between overand under-prediction. This generally improving trend is also reflected in Theil statistics. Interestingly, the pattern of Theil statistics for both France and the US show a markedly improving trend since 1994, in contrast to that seen in the UK.

Panels in Figure 8 show forecast errors for the long-term interest rate. No particularly discernable patterns can be seen for France or the US. They are relatively more well-behaved in comparison to those for the UK.

In general, forecast errors from models for France and the US tend to be more well behaved

for hyper-parameter estimations--RMSE minimization procedure described in 'Estimation' section--are identical to those for the UK case. 
and smaller in absolute size since 1993. This suggests that the relative fit of the UK model is worse than those for the two other countries. Despite the similarity seen between most G-7 countries by way of low inflation, a more systematic comparison points to some perceptible differences between the inflation targeting UK and non-inflation targeting France and US.

To summarize, the recent mild inflation seen in the latter two economies was not unusual in light of their experiences since the mid-1980s. However, in the case of the UK, it has been unusual. That is, the dynamic economic relationship of the 1980 s captured by the model can not explain the recent inflation behavior seen since the adoption of the IT regime. ${ }^{18}$

\section{Conclusion}

This paper examined the UK's experience with the IT monetary regime that started in 1993 and finds evidence that the regime has had some measurable effect on how monetary policy and inflation interact. That is, despite a monetary policy stance that has not been as tight as the model would suggest, inflation remained close to the model's forecast. It took less monetary tightening to obtain a favorable inflation outcome. This might be reflecting extant credibility effect of IT as markets expect future monetary policy to be conducted along a path compatible with maintaining lower inflation.

Identical exercises were repeated for France and the US, countries that have not adopted IT but have experienced low inflation in the recent period. Results show that, unlike the UK's case, recent

\footnotetext{
${ }^{18}$ There exist some interesting differences within IT countries. The UK's IT regime differs from those of other countries in that it specifies only the goal to be achieved. New Zealand and Canada not only specify their explicit goals, but also specify an explicit penalty for failure (New Zealand), and grant a great deal more autonomy to the central banks (New Zealand, Canada). Thus, in some sense, the UK's arrangement is less binding. Such differences notwithstanding, this paper's finding indicates an enhanced credibility of monetary policy. Hence, perhaps the fact that IT offers an objective and explicit yardstick that monetary authorities' performance can be held to is the key. In the event of failure to meet the goal, reactions by politicians and financial markets could deal severe repercussions to policy makers. For example, an increase in the government's funding cost would be one consequence.
} 
low inflation in these economies has not been unusual when compared to forecasts from models designed to fit the second half of the 1980s. That is, given the level of inflation, the degree of actual monetary policy tightness (measured in terms of short-term interest rate) is about what the model expects.

Despite the findings of this exercise, however, indicators of long-term inflation expectations have not been unanimous or unambiguous in pointing to low future inflation in the 1990s. Survey measures of inflation expectations also have declined at a glacial pace. These suggest that establishing the monetary policy credibility over the long-term horizon is a highly costly commodity. 


\section{References}

Ammer, J., and R. Freeman (1995), "Inflation Targets in the 1990s: The Experiences of new Zealand, Canada, and the United Kingdom," Journal of Economics and Business 47 pp. 165-192.

Bowen, A. (1995), "Inflation Targetry in the United Kingdom," in Haldane, A. G. ed. Targeting Inflation Bank of England, London.

Doan, T., R. Litterman, and C. A. Sims (1984), "Forecasting and Conditional Projection Using Realistic Prior Distributions," Econometric Reviews vol. 3, pp. 1-100.

Freeman, R., and J. Willis (1995), "Targeting Inflation in the 1990s: Recent Challenges," FRB International Finance Discussion Paper No.525.

Fischer, S. (1994), "Modern Central Banking," paper presented at the Bank of England Tercentenary conference.

Haldane, A. G. ed. (1995) Targeting Inflation Bank of England, London.

Hall, R., and N. Gregory Mankiw (1994), "Nominal Income Targeting," in N. Gregory Mankiw, ed., Monetary Policy, University of Chicago Press, Chicago.

Inflation Reports (1996), The Bank of England. August.

King, M. A.(1994), "Monetary Policy in the UK," Fiscal Studies vol. 15, no. 3, pp.109-128.

Leiderman. L., and L. Svensson eds.(1995), Inflation Targets, CEPR, London.

Litterman, R. (1981), "A Bayesian Procedure for Forecasting with Vector Autoregressions," FRB of Minneapolis Working Paper.

Mayes, D., and Bryan Chapple (1995), "The Costs and Benefits of Disinflation: a Critique of the Sacrifice Ratio," Reserve Bank Bulletin, Reserve Bank of New Zealand, pp. 9-21.

McCallum, B. (1995), "Inflation Targeting in Canada, New Zealand, Sweden, the United Kingdom, and in General," mimeo, Carnegie Mellon University.

Sims, C. A. (1980), "Macroeconomics and Reality," Econometrica , vol. 48, pp. 1-49.

Svensson, Lars (1996), "Inflation Forecast Targeting: Implementing and Monitoring Inflation Targets," mimeo, Institute for International Economic Studies, Stockholm University.

(1996), "Optimal Inflation Targets, 'Conservative Central Banks, and Linear Inflation Contracts," NBER Working Paper No. 5251.

(1993), "The Simplest Test of Target Credibility," NBER Working Paper No.4604.

Temperton, P. (1991), UK Monetary Policy, St. Martin's Press. 
Theil, Henri (1972), Principles of Econometrics. New York: Wiley

Woodford, M. (1994), "Nonstandard Indicators for Monetary Policy: Can Their Usefulness be Judged from Forecasting Regressions?" in N. Gregory Mankiw, ed., Monetary Policy, University of Chicago Press, Chicago. 
Table 1: One- to four-quarter ahead Forecast Error Statistics (1985Q1-90Q2)

\begin{tabular}{|c|c|c|c|c|c|}
\hline Variables & $\begin{array}{l}\text { Forecast } \\
\text { horizon }\end{array}$ & Mean Errors & $\begin{array}{l}\text { Mean } \\
\text { Absolute } \\
\text { Errors }\end{array}$ & $\begin{array}{l}\text { Root Mean } \\
\text { Squared } \\
\text { Errors }\end{array}$ & $\begin{array}{l}\text { Theil's U- } \\
\text { Statistics }\end{array}$ \\
\hline \multirow{2}{*}{$\begin{array}{l}\text { Output } \\
\text { growth }(y)\end{array}$} & 1-quarter & 0.878 & 2.310 & 2.851 & 0.829 \\
\hline & 4-quarter & 0.729 & 2.107 & 2.499 & 0.766 \\
\hline \multirow{2}{*}{$\begin{array}{l}\text { Inflation in } \\
\operatorname{RPIX}(\pi)\end{array}$} & 1 -quarter & -0.131 & 1.233 & 1.560 & 0.800 \\
\hline & 4-quarter & -0.366 & 1.123 & 1.514 & 0.608 \\
\hline \multirow{2}{*}{$\begin{array}{l}\text { Unemploym- } \\
\text { ent }(u n)\end{array}$} & 1-quarter & -0.009 & 0.013 & 0.016 & 0.379 \\
\hline & 4-quarter & -0.098 & 0.106 & 0.122 & 0.712 \\
\hline \multirow{2}{*}{$\begin{array}{l}\text { Exchange } \\
\text { Rate }(e x)\end{array}$} & 1-quarter & -0.013 & 0.032 & 0.041 & 1.088 \\
\hline & 4-quarter & -0.058 & 0.071 & 0.091 & 1.230 \\
\hline \multirow{2}{*}{$\begin{array}{l}\text { Short-term } \\
\text { interest (sr) }\end{array}$} & 1-quarter & 0.016 & 0.097 & 0.123 & 1.107 \\
\hline & 4-quarter & 0.022 & 0.162 & 0.182 & 0.891 \\
\hline \multirow{2}{*}{$\begin{array}{l}\text { Long-term } \\
\text { interest }(I r)\end{array}$} & 1-quarter & -0.003 & 0.037 & 0.046 & 0.882 \\
\hline & 4-quarter & -0.028 & 0.055 & 0.063 & 0.784 \\
\hline
\end{tabular}

1. There are 22 and 19 observations respectively for 1 and 4 quarter ahead forecasts. 
Figure 1: Dâta Plot

Output Growth

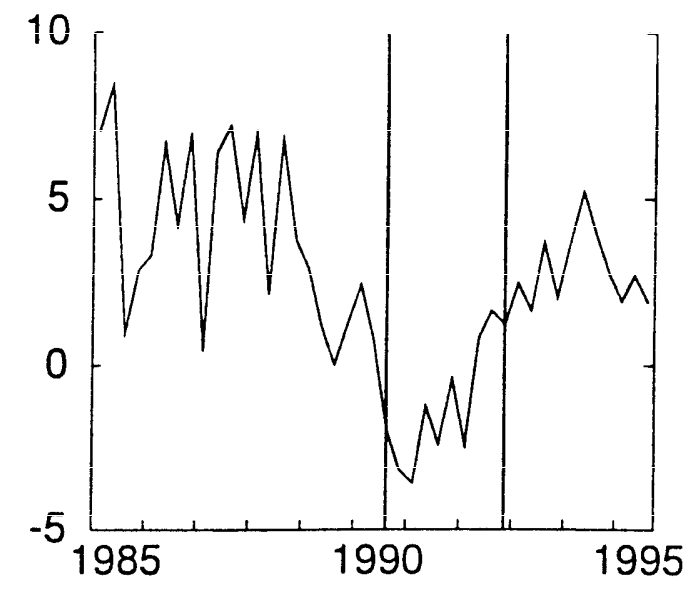

Pound (weighted average)
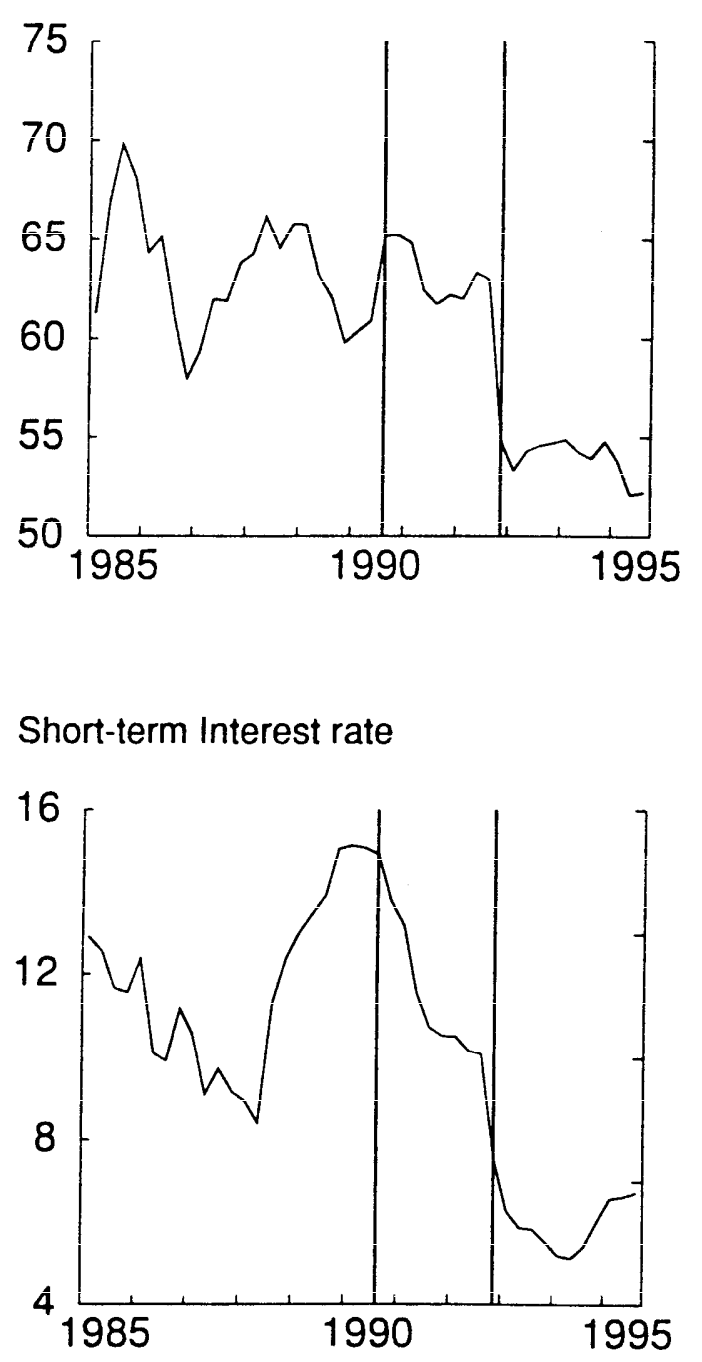

Inflation

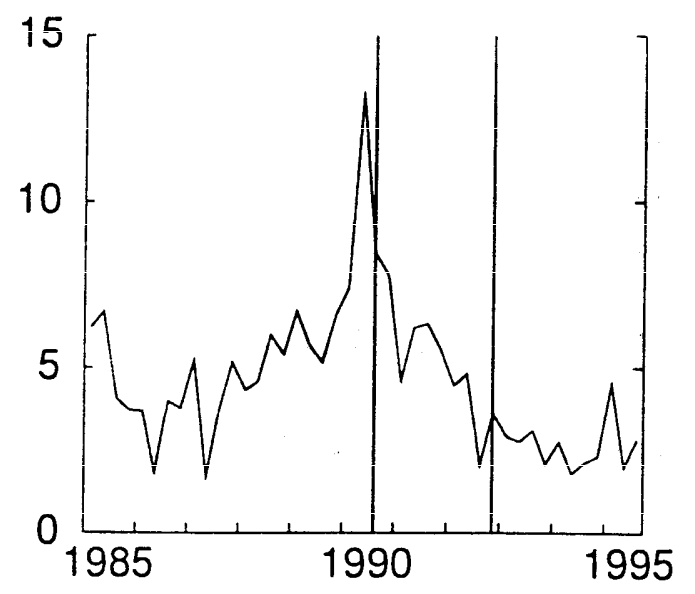

Unemployment rate

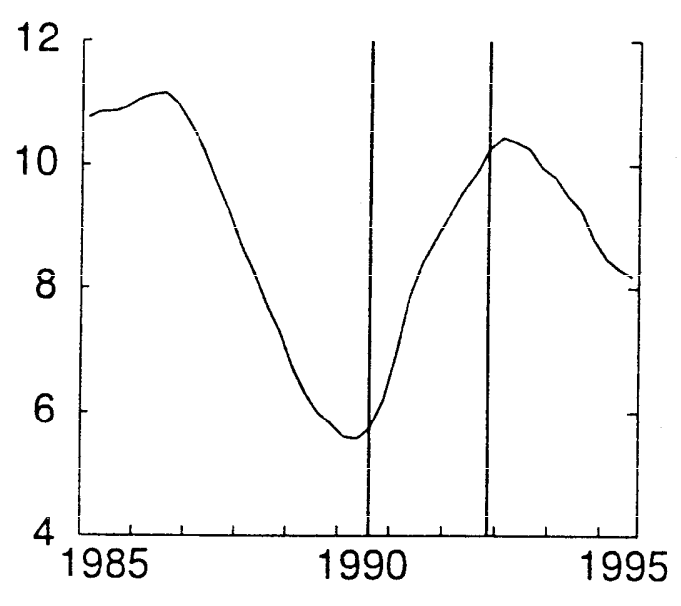

Long-term Interest rate

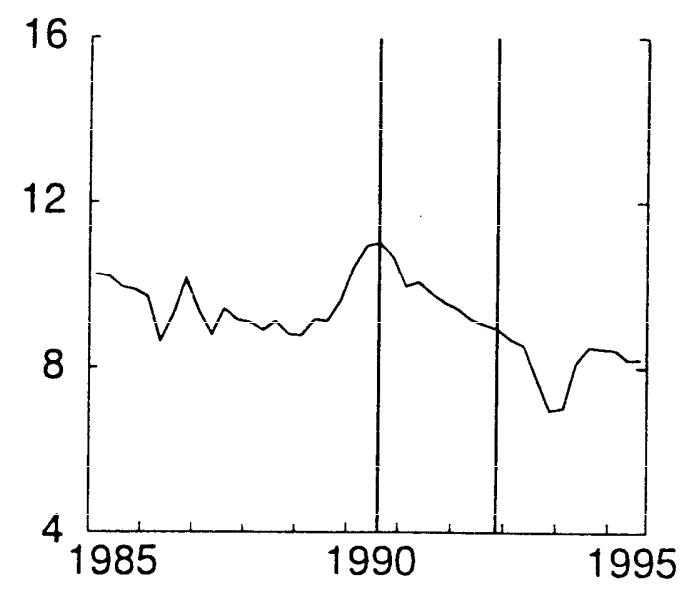


Figure 2: Residuals

From Model Estimated 72Q1-90Q2

Inflation

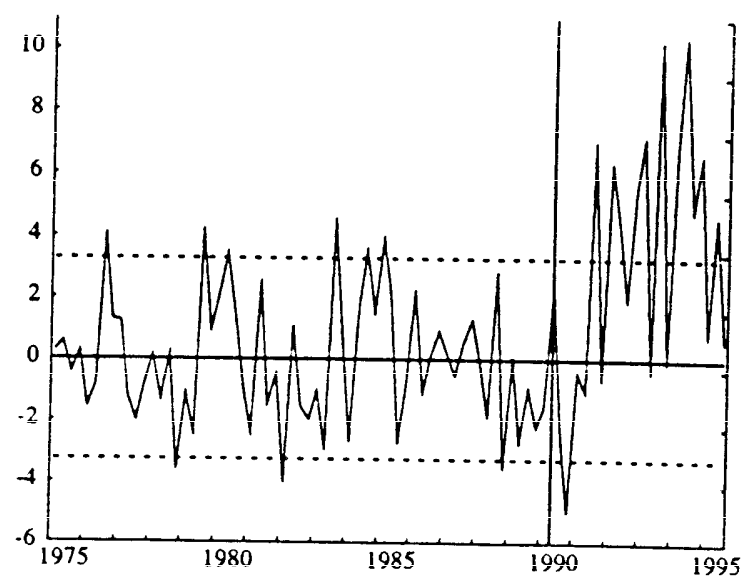

Short-term Interest Rate

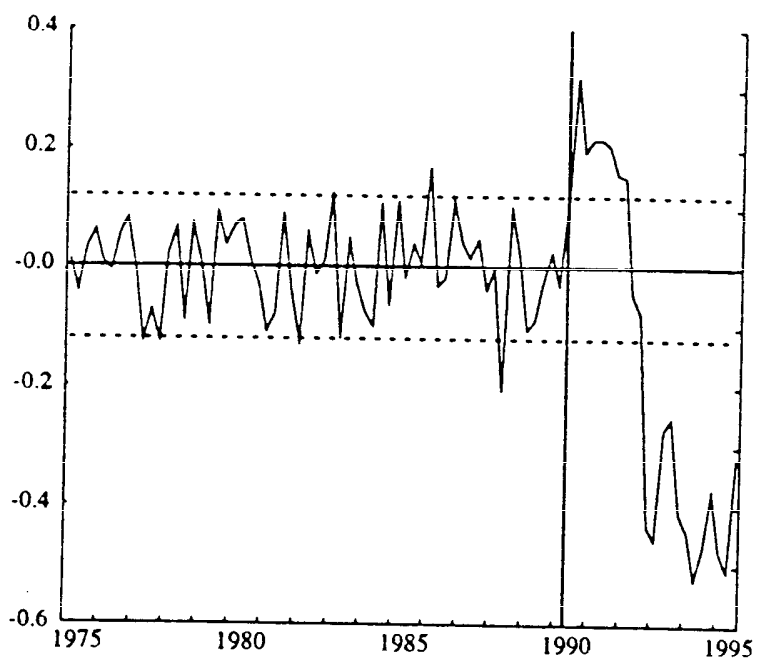

Long-term Interest Rate

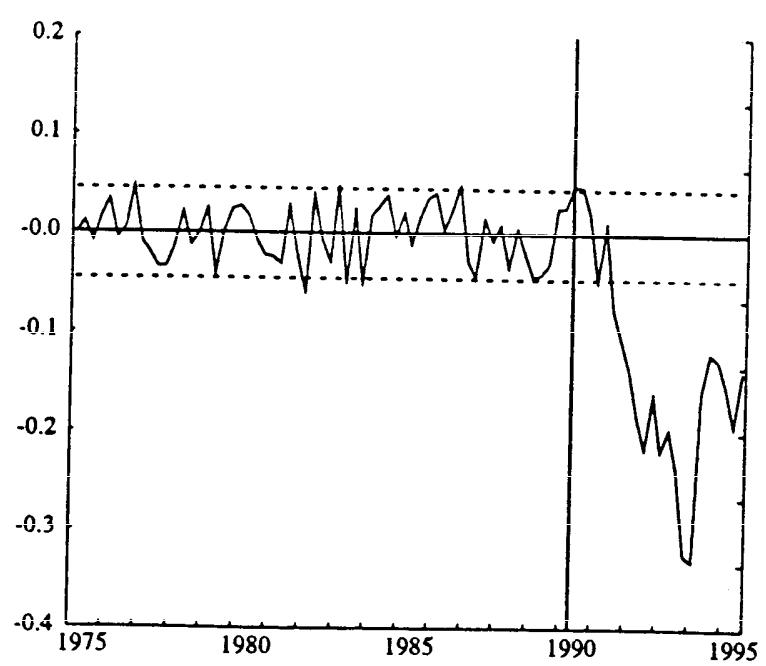

From Model Estimated 72Q1-92Q3

Inflation

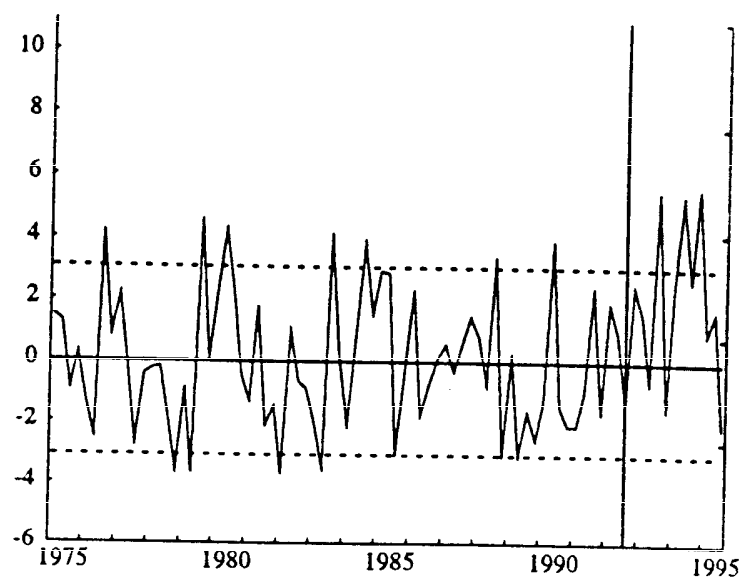

Short-term Interest Rate

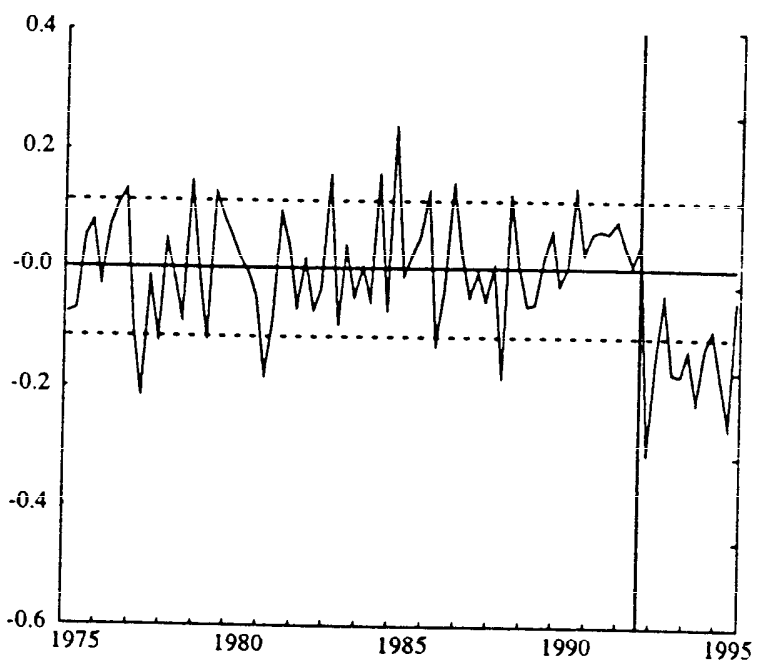

Long-term Interest Rate

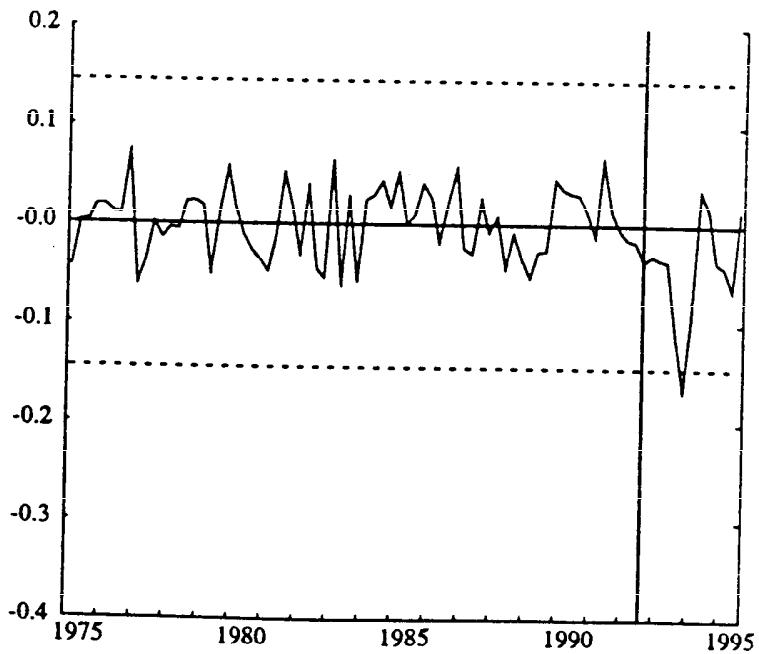



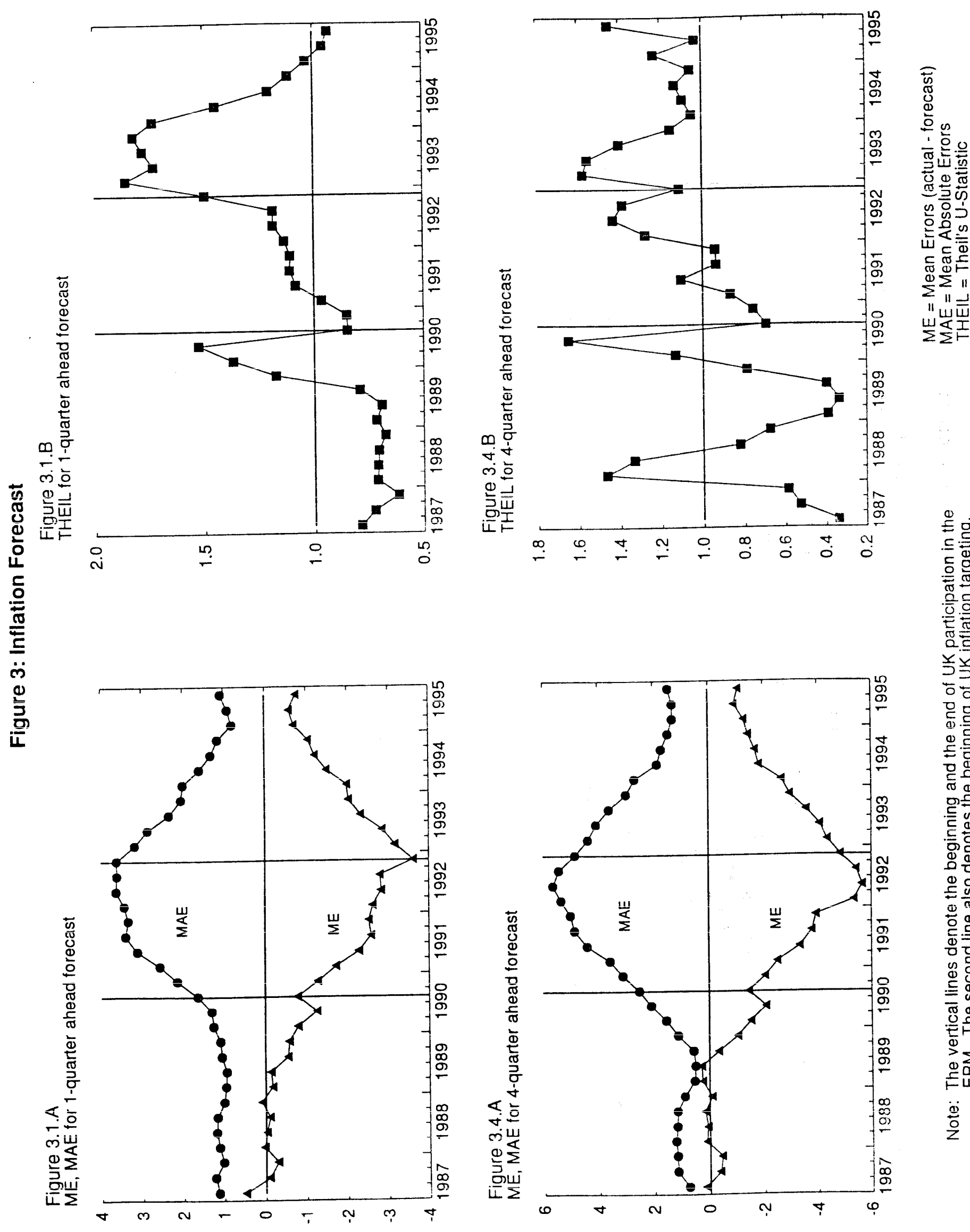

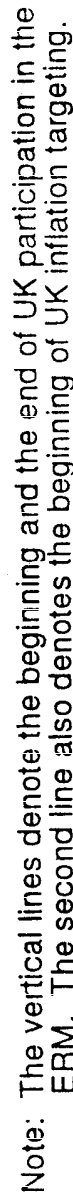



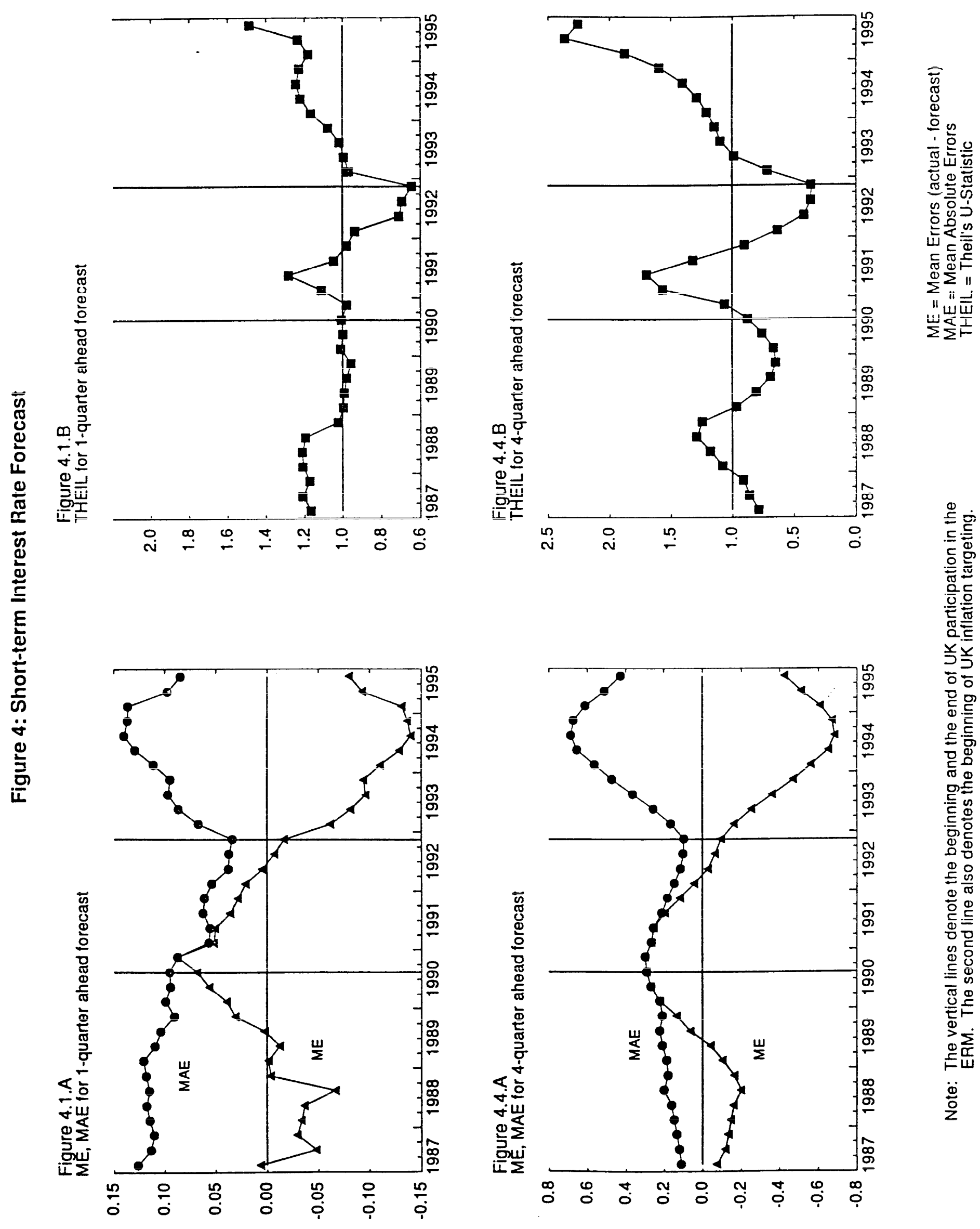

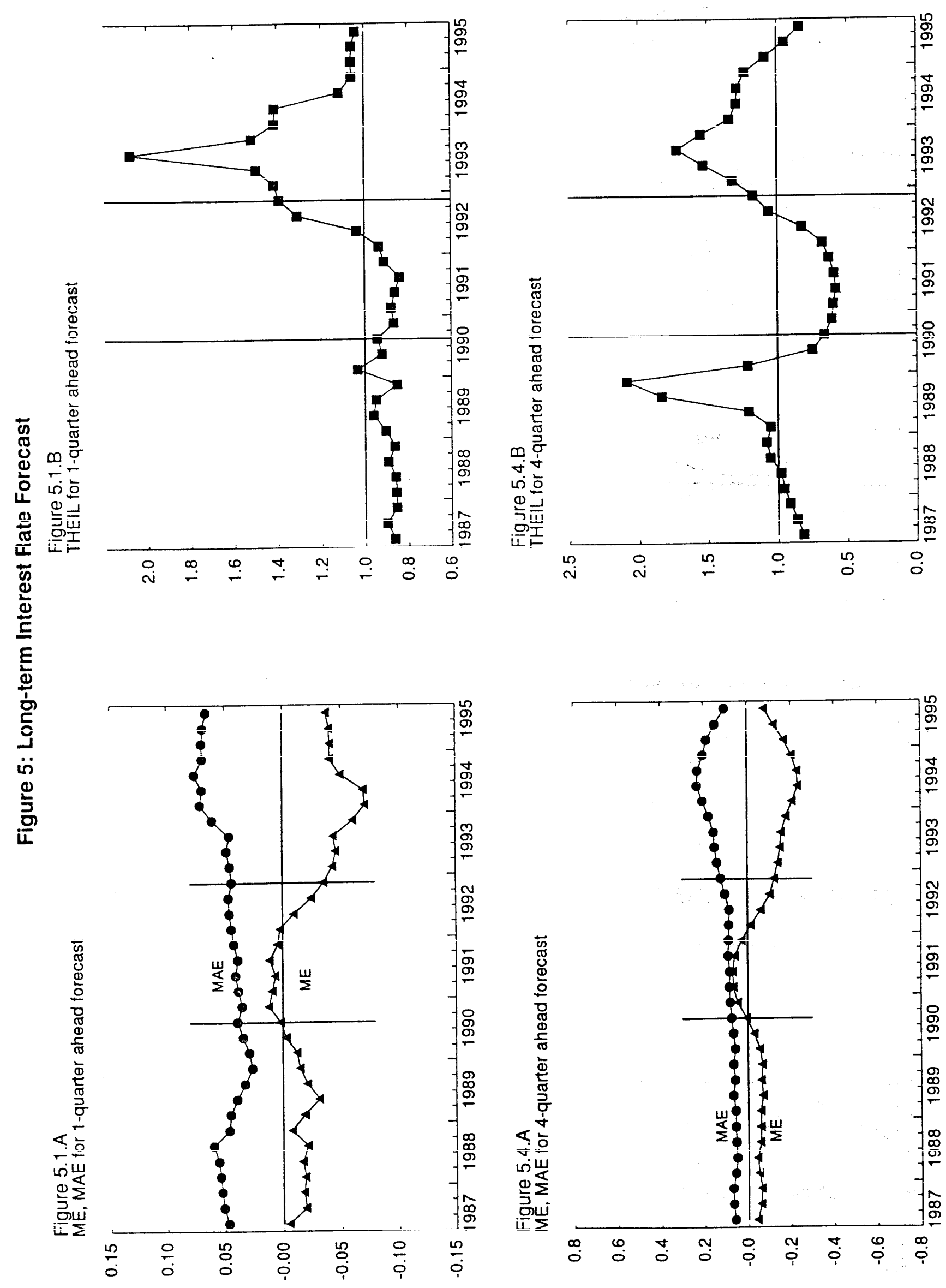

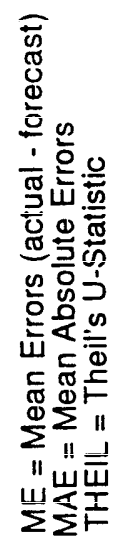
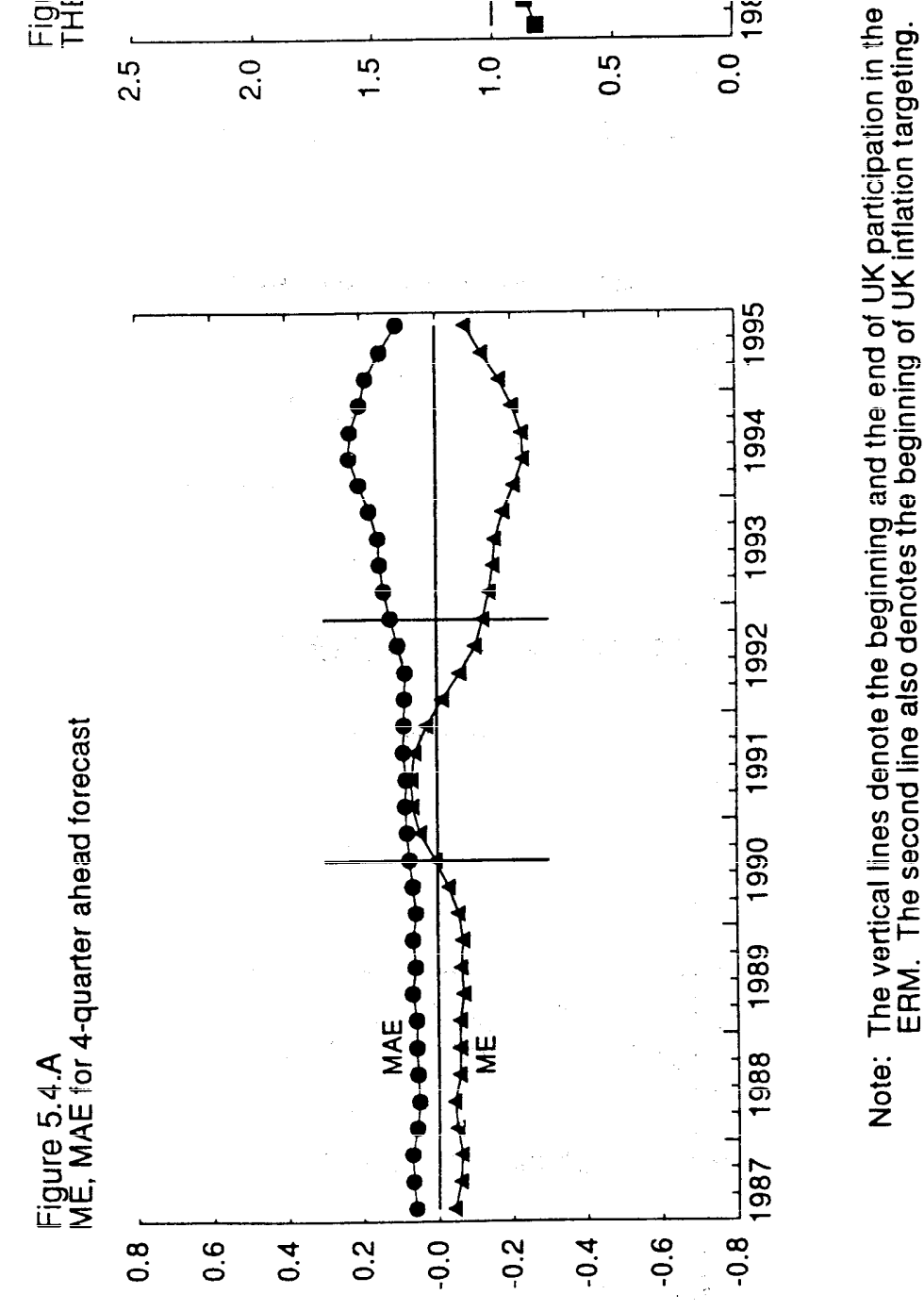

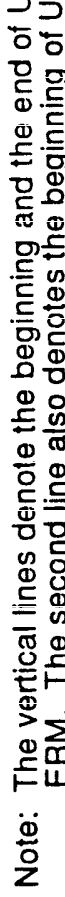


Figure 6 Inflation: France (Dotted line for the UK)

ME, MAE for 1-quarter ahead forecast

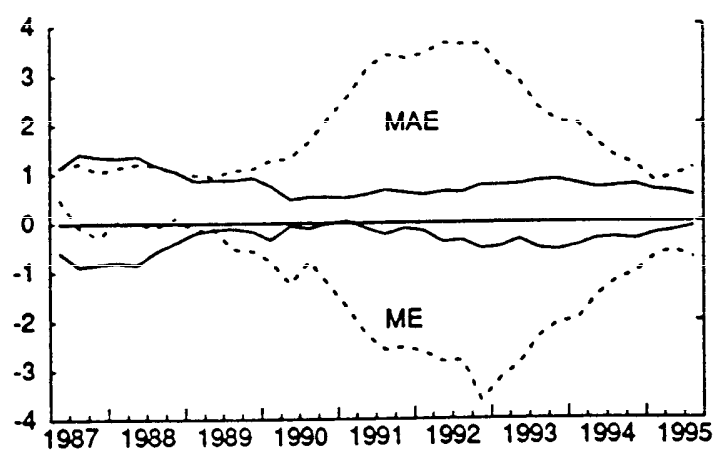

ME, MAE for 4-quarter ahead forecast

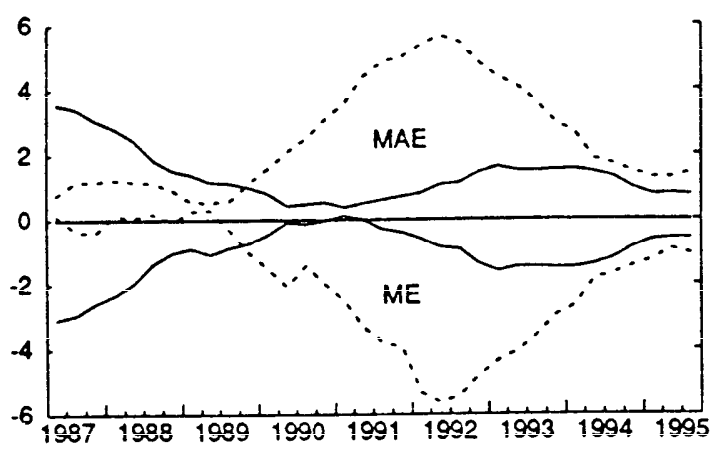

ME, MAE for 1-quarter ahead forecast

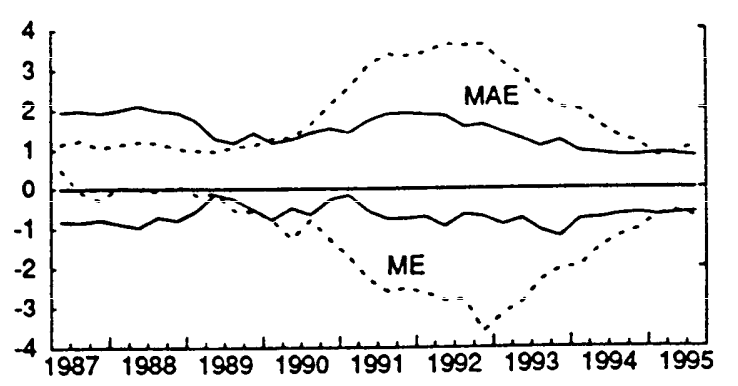

ME, MAE for 4-quarter ahead forecast

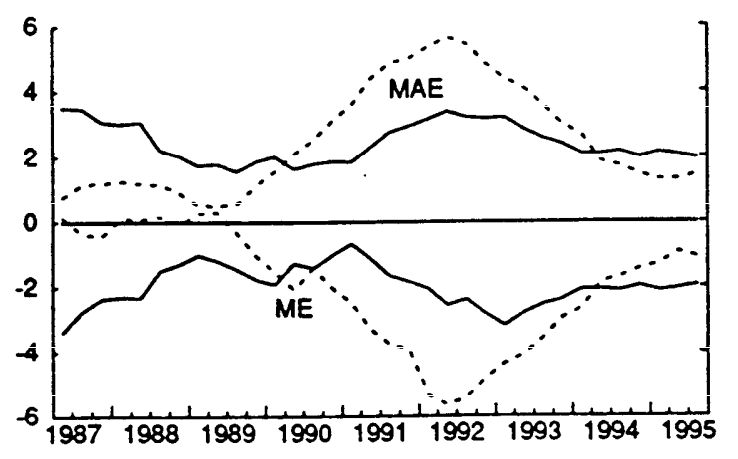

THEIL for 1-quarter ahead forecast
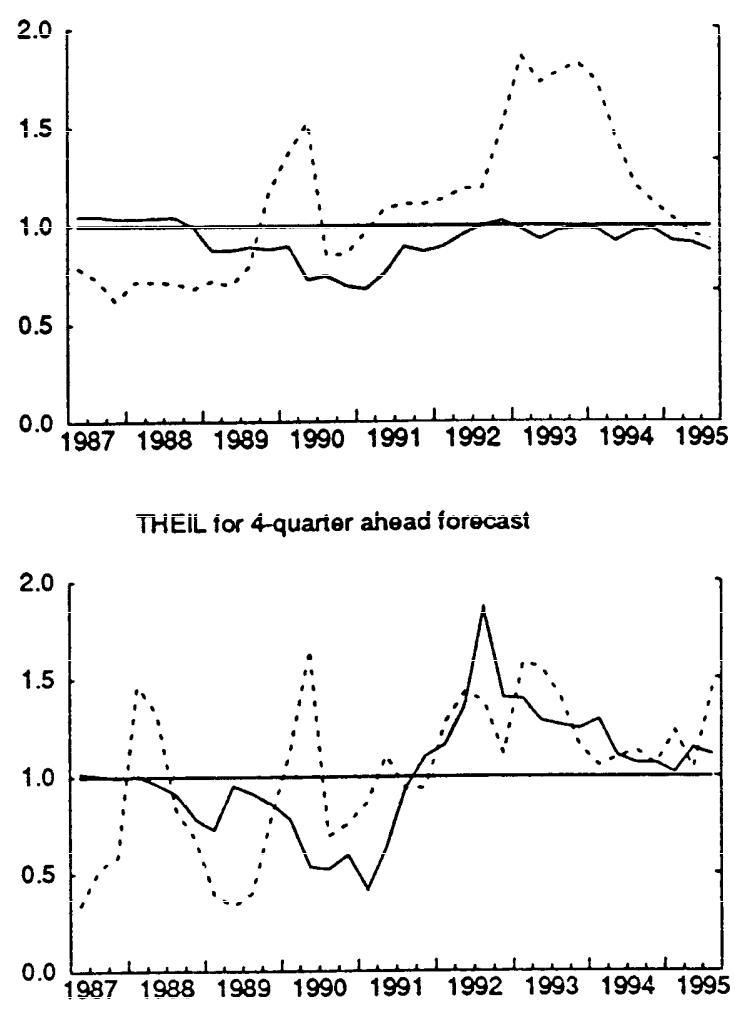

US

THEIL for 1-quarter ahead forecast
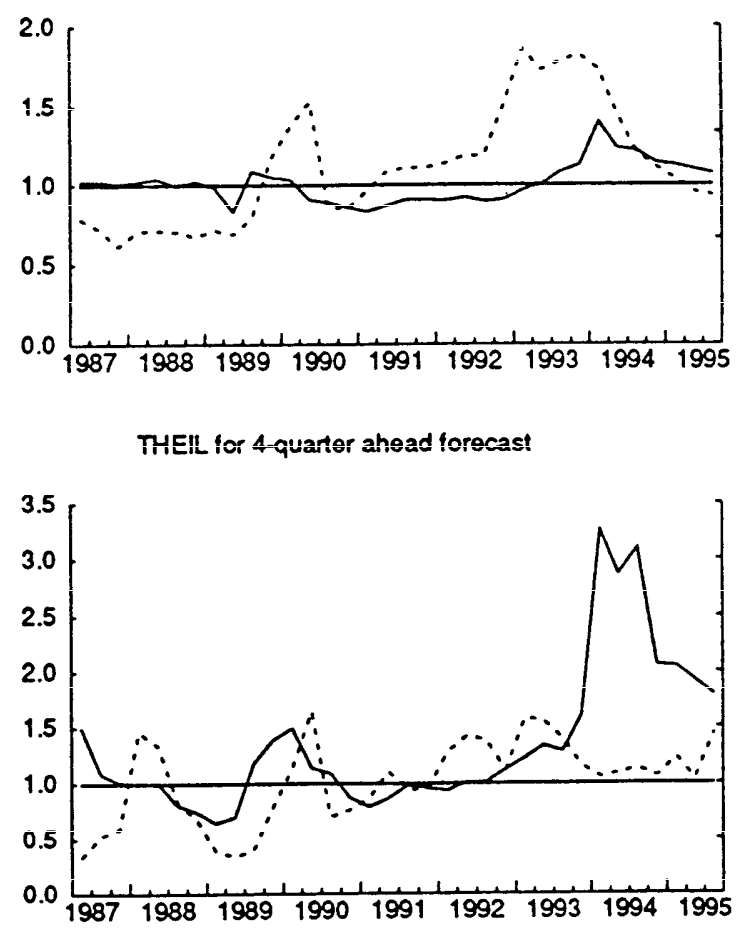
Figure 7 Short-term interest Rate: France (Dotted line for the UK)

ME, MAE for 1-quarter ahead forecast
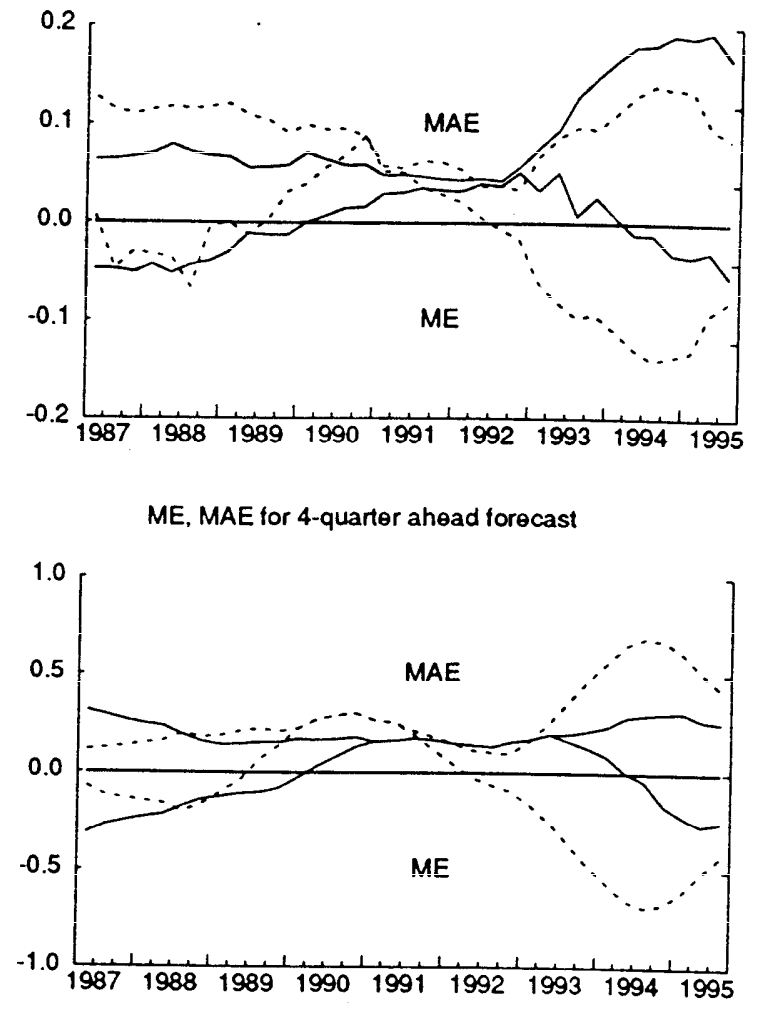

ME, MAE for 1-quarter ahead forecast
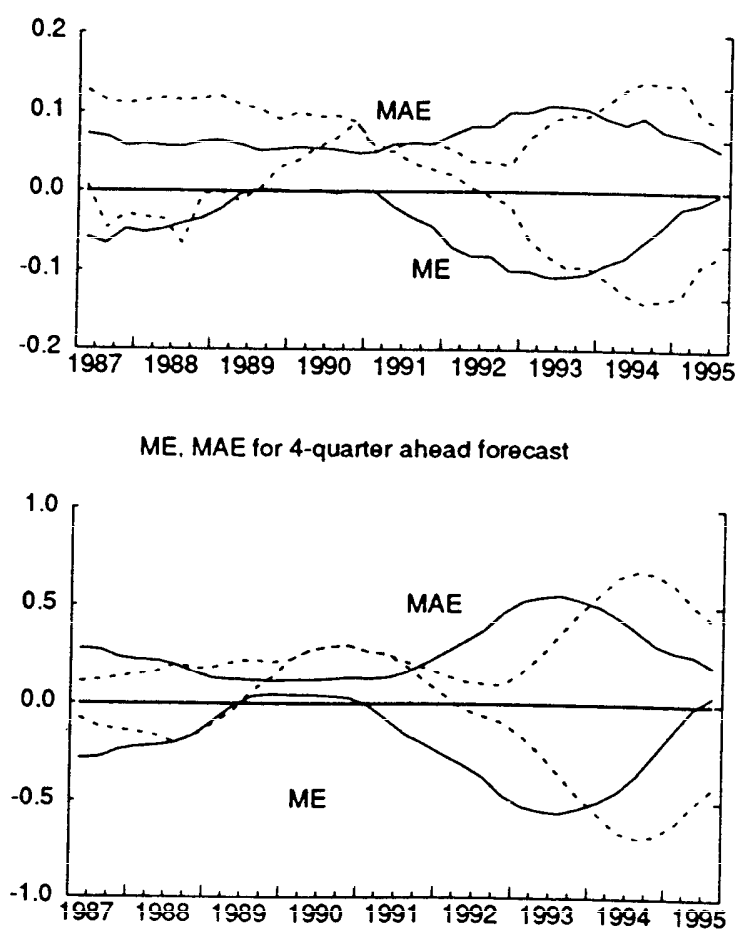

ME = Mean Errors

MÁE = Mean Absolute Errors

THEIL = Theil's U-Statistic
THEIL for 1-quarter ahead forecast
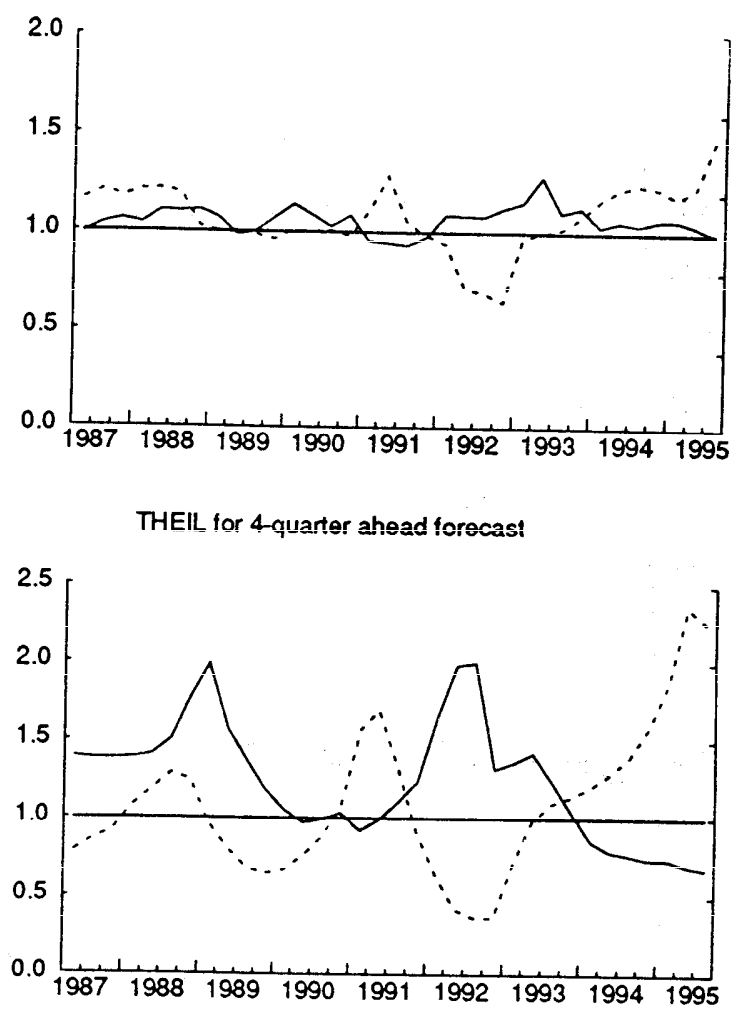

US

THEIL for 1-quarter ahead forecast

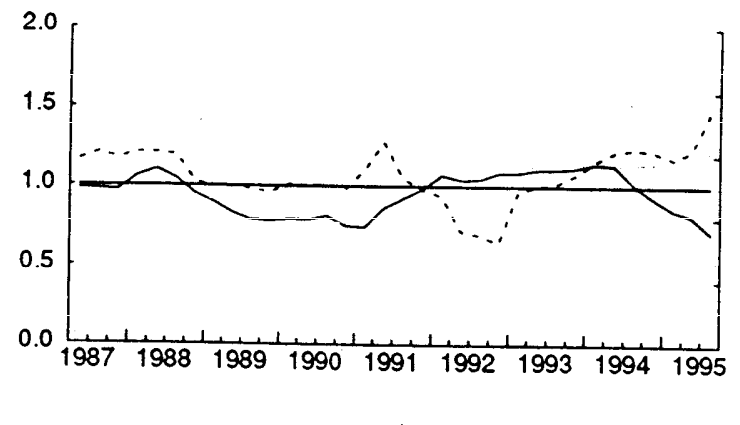

THEIL for 4-quarter ahead forecast

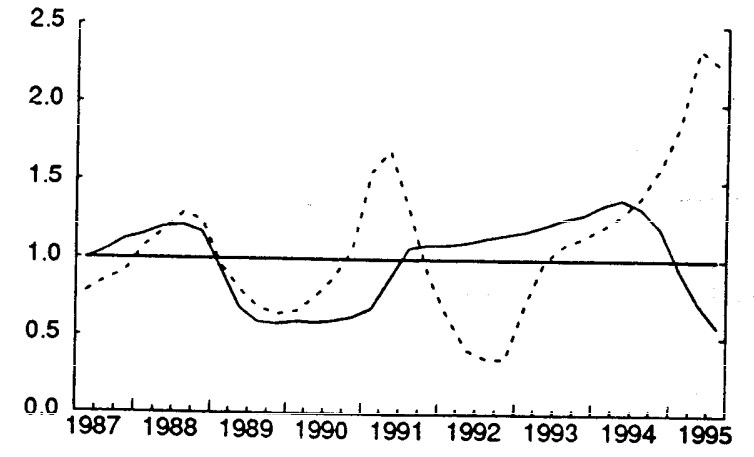


Figure 8 Long-term interest Rate: France (Dotted line for the UK)

ME. MAE for 1-quarter ahead forecast
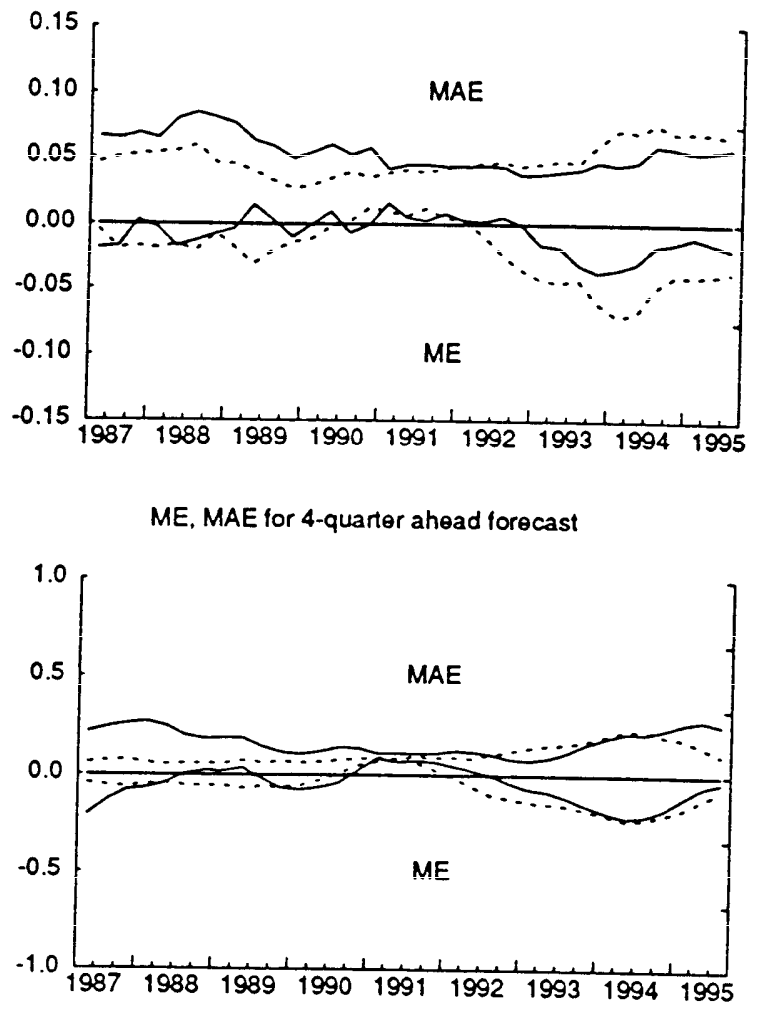

ME. MAE for 1-quarter ahead forecast

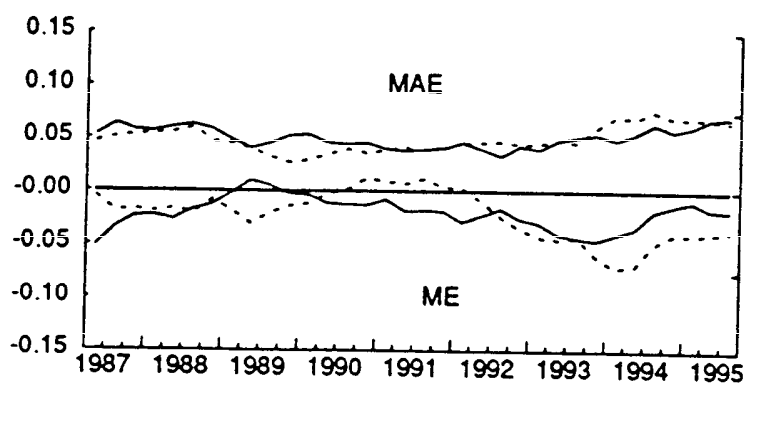

ME. MAE for 4-quarter ahead forecast

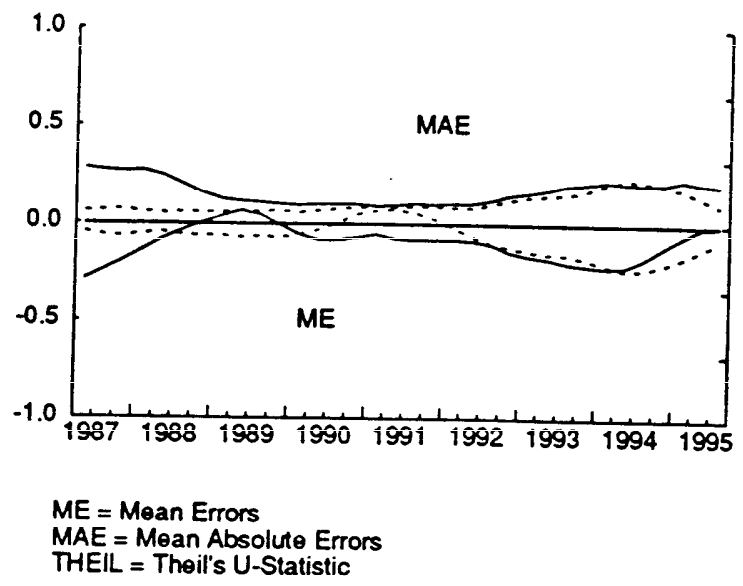

THEIL for 1-quarter ahead forecast
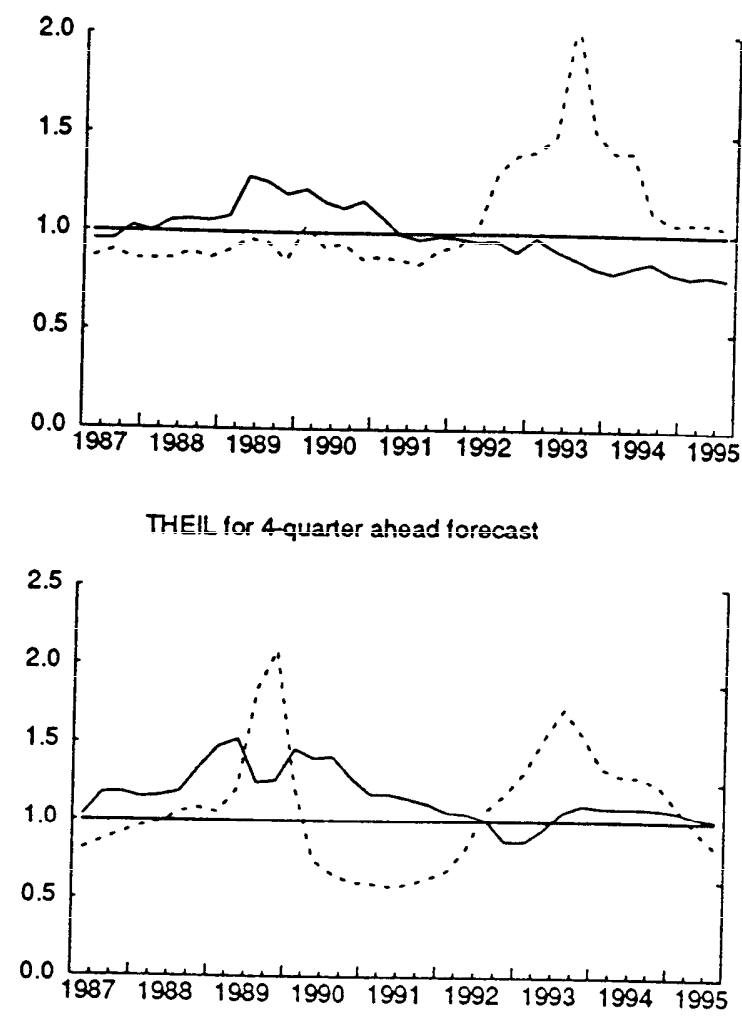

US

THEIL for 1-quarter ahead forecast
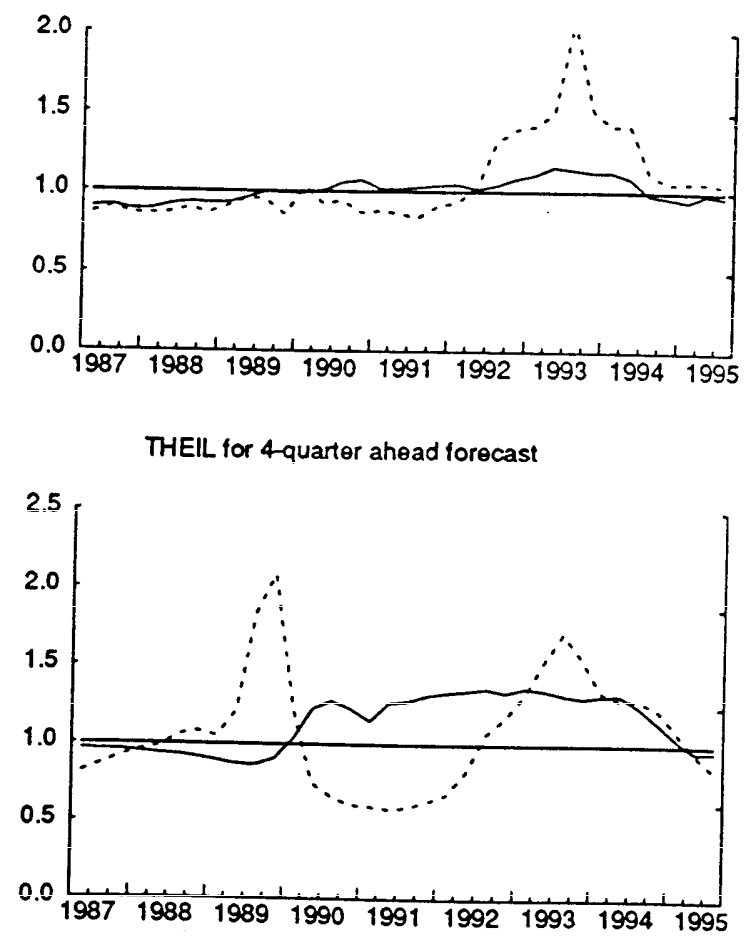


\section{International Finance Discussion Papers}

IFDP

Number

$\underline{\text { Titles }}$

$\underline{\text { Author(s) }}$

$\underline{1996}$

565 Some Evidence on the Efficacyof the UK Inflation

Targeting Regime: An Out-of-Sample Forecast

Approach

564 The Use of the Parallel Market Rate as a Guide

to Setting the Official Exchange Rate

Chan Huh

Country Fund Discounts and the Mexican Crisis of

December 1994: Did Local Residents Turn

Pessimistic Before International Investors?

562 Eastern European Export Performance during

the Transition

Nita Ghei

Steven B. Kamin

Jeffrey A. Frankel

Sergio L. Schmukler

Nathan Sheets

Simona Boata

561 Inflation-Adjusted Potential Output

Jane T. Haltmaier

560 The Management of Financial Risks at German Nonfinancial Firms: The Case of Metallgesellschaft

Allen B. Frankel

David E. Palmer

559 Broad Money Demand and Financial Liberalization in Greece

Neil R. Ericsson

Sunil Sharma

558 Stockholding Behavior of U.S. Households: Evidence from the 1983-89 Survey of Consumer Finances

Carol C. Bertaut

557 Firm Size and the Impact of Profit-Margin Uncertainty on Investment: Do Financing Constraints Play a Role?

Vivek Ghosal

Prakash Loungani

556 Regulation and the Cost of Capital in Japan: A Case Study

John Ammer

Michael S. Gibson

555 The Sovereignty Option: The Quebec Referendum and

Michael P. Leahy

Market Views on the Canadian Dollar

Charles P. Thomas

554 Real Exchange Rates and Inflation in Exchange-Rate

Based Stabilizations: An Empirical Examination

Steven B. Kamin

553

Macroeconomic State Variables as Determinants of Asset Price Covariances

John Ammer

Please address requests for copies to International Finance Discussion Papers, Division of International Finance, Stop 24, Board of Governors of the Federal Reserve System, Washington, DC 20551. 


\section{International Finance Discussion Papers}

IFDP

Number $\underline{\text { Titles }}$

$\underline{1996}$

552 The Tequila Effect: Theory and Evidence from Argentina

551 The Accumulation of Human Capital: Alternative Methods and Why They Matter
Alternatives in Human Capital Accumulation: Implications for Economic Growth

More Evidence on the Link between Bank Health and Investment in Japan

The Syndrome of Exchange-Rate-Based Stabilization and the Uncertain Duration of Currency Pegs

German Unification: What Have We Learned from Multi-Country Models?

Returns to Scale in U.S. Production: Estimates and Implications

Mexico's Balance-of-Payments Crisis: A Chronicle of Death Foretold

The Twin Crises: The Causes of Banking and Balance-of-Payments Problems

High Real Interest Rates in the Aftermath of Disinflation: Is it a Lack of Credibility?

\section{Precautionary Portfolio Behavior from a Life-Cycle} Perspective

Using Options Prices to Infer PDF's for Asset Prices: An Application to Oil Prices During the Gulf Crisis

Monetary Policy in the End-Game to Exchange-Rate Based Stabilizations: The Case of Mexico

Comparing the Welfare Costs and the Initial Dynamics of Alternative Temporary Stabilization Policies
Author(s)

Martín Uribe

Murat F. Iyigun

Ann L. Owen

Murat F. Iyigun

Ann L. Owen

Michael S. Gibson

Enrique G. Mendoza Martin Uribe

Joseph E. Gagnon

Paul R. Masson

Warwick J. McKibbin

Susanto Basu

John G. Fernald

Guillermo Â. Calvo Enrique G. Mendoza

Graciela L. Kaminsky Carmen M. Reinhart

Graciela L. Kaminsky Leonardo Leiderman

Carol C. Bertaut Michael Haliassos

William R. Melick Charles P. Thomas

Steven B. Kamin John H. Rogers

Martin Uribe 


\section{International Finance Discussion Papers}

IFDP

Number $\underline{\text { Titles }}$

1996

538 Long Memory in Inflation Expectations: Evidence from International Financial Markets

537 Using Measures of Expectations to Identify the Effects of a Monetary Policy Shock

Regime Switching in the Dynamic Relationship between the Federal Funds Rate and Innovations in Nonborrowed Reserves

535 The Risks and Implications of External Financial Shocks: Lessons from Mexico

534 Currency Crashes in Emerging Markets: An Empirical Treatment

533 Regional Patterns in the Law of One Price: The Roles of Geography Vs. Currencies

Author(s)

Joseph E. Gagnon

Allan D. Brunner

Chan Huh

Edwin M. Truman

Jeffrey A. Frankel Andrew K. Rose

Charles Engel John H. Rogers 